\title{
Functional characterization of a highly specific L-arabinose transporter from Trichoderma reesei
}

\author{
Sami Havukainen' ${ }^{1}$ Jonai Pujol-Giménez ${ }^{2,3}$, Mari Valkonen ${ }^{1}$, Matthias A. Hediger, ${ }^{2,3}$ and \\ Christopher P. Landowski ${ }^{*}$ (I)
}

\begin{abstract}
Background: Lignocellulose biomass has been investigated as a feedstock for second generation biofuels and other value-added products. Some of the processes for biofuel production utilize cellulases and hemicellulases to convert the lignocellulosic biomass into a range of soluble sugars before fermentation with microorganisms such as yeast Saccharomyces cerevisiae. One of these sugars is L-arabinose, which cannot be utilized naturally by yeast. The first step in L-arabinose catabolism is its transport into the cells, and yeast lacks a specific transporter, which could perform this task.
\end{abstract}

Results: We identified Trire2_104072 of Trichoderma reesei as a potential L-arabinose transporter based on its expression profile. This transporter was described already in 2007 as D-xylose transporter XLT1. Electrophysiology experiments with Xenopus laevis oocytes and heterologous expression in yeast revealed that Trire2_104072 is a high-affinity L-arabinose symporter with a $K_{\mathrm{m}}$ value in the range of $\sim 0.1-0.2 \mathrm{mM}$. It can also transport D-xylose but with low affinity $\left(K_{\mathrm{m}} \sim 9 \mathrm{mM}\right)$. In yeast, L-arabinose transport was inhibited slightly by $\mathrm{D}$-xylose but not by $\mathrm{D}$-glucose in an assay with fivefold excess of the inhibiting sugar. Comparison with known L-arabinose transporters revealed that the expression of Trire2_104072 enabled yeast to uptake L-arabinose at the highest rate in conditions with low extracellular L-arabinose concentration. Despite the high specificity of Trire2_104072 for L-arabinose, the growth of its T. reesei deletion mutant was only affected at low L-arabinose concentrations.

Conclusions: Due to its high affinity for L-arabinose and low inhibition by D-glucose or D-xylose, Trire2_104072 could serve as a good candidate for improving the existing pentose-utilizing yeast strains. The discovery of a highly specific L-arabinose transporter also adds to our knowledge of the primary metabolism of T. reesei. The phenotype of the deletion strain suggests the involvement of other transporters in L-arabinose transport in this species.

Keywords: Trichoderma reesei, Transmembrane transport, Arabinose transporter, Pentose fermentation

\section{Background}

Lignocellulose biomass has gained considerable attention as a feedstock for bioprocesses. It is renewable and abundant all over the world, and its utilization as a feedstock

*Correspondence: christopher.landowski@vtt.fi

${ }^{1}$ VTT Technical Research Center of Finland Ltd, Tietotie 2, 02150 Espoo, Finland

Full list of author information is available at the end of the article does not interfere with food production, as is the case for the starch containing feedstocks used to create 1st generation biofuels. Lignocellulose biomass consists mainly of polysaccharides and lignin. The polysaccharides contain plant cell wall polysaccharides (cellulose, hemicellulose, pectin) and storage polysaccharides (starch, inulin), of which the former are of particular importance for bioprocess feedstock purposes [1]. One way to convert lignocellulose biomass into value-added compounds, original author(s) and the source, provide a link to the Creative Commons licence, and indicate if changes were made. The images or other third party material in this article are included in the article's Creative Commons licence, unless indicated otherwise in a credit line to the material. If material is not included in the article's Creative Commons licence and your intended use is not permitted by statutory regulation or exceeds the permitted use, you will need to obtain permission directly from the copyright holder. To view a copy of this licence, visit http://creativecommons.org/licenses/by/4.0/. The Creative Commons Public Domain Dedication waiver (http://creativeco mmons.org/publicdomain/zero/1.0/) applies to the data made available in this article, unless otherwise stated in a credit line to the data. 
such as biofuels, is its enzymatic hydrolysis followed by fermentation. The most studied organism for the fermentation step is the yeast Saccharomyces cerevisiae, since it naturally produces high amounts of ethanol, has long history of industrial use, and is tolerant to growth inhibitors (e.g. acetic acid) which are produced during the pretreatment of the biomass $[2,3]$.

The sugar composition of the lignocellulose hydrolysate depends on the type of plant raw material. The main sugars in monocots, which are considered the main renewable-energy crop, are the hexose D-glucose and the pentoses $\mathrm{D}$-xylose and L-arabinose $[4,5]$. Complete substrate utilization is required for an economically competitive biofuel process, but wild-type $S$. cerevisiae is not able to consume these pentose sugars [6]. To circumvent this issue, numerous studies have investigated metabolic engineering of yeast for the utilization of D-xylose and L-arabinose (Reviewed in Refs. [7, 8]). The utilization of D-xylose has received more attention, as in many biomasses it is present in higher abundance than L-arabinose [8, 9]. Nevertheless, some pectin-rich waste biomasses from the food industry (e.g. orange peels, sugar beet pulp) contain higher amounts of L-arabinose than D-xylose [10]. These biomasses have gained interest as industrial feedstocks due to their low lignin content, which decreases the need for pretreatment $[11,12]$. They are also abundantly available at low cost, and their utilization does not interfere with food production [11-13].

Besides pathway engineering, several studies have focused on finding an efficient uptake system for D-xylose and L-arabinose (Reviewed in Ref. [9]). Some of the endogenous sugar transporters of yeast can transport these sugars, but with low affinity and thus the transport is inhibited by D-glucose $[9,14,15]$. Although it has been stated that transport is currently not the limiting factor in either D-xylose or L-arabinose fermentation, a highaffinity pentose transporter could improve growth in conditions where the substrate concentration is low and enable simultaneous utilization of $\mathrm{D}$-glucose and pentoses $[8,9,16]$. Several heterologous pentose transporters have been characterized to investigate their suitability for such purpose [9]. L-Arabinose transporters have thus far been found from yeasts $[15,17,18]$, fungi $[16,19,20]$, bacteria [21-24] and from the plant Arabidopsis thaliana $[15,25]$. However, many of these transporters suffer from low expression levels in yeast and from inhibition of L-arabinose transport by D-glucose. [9].

Trichoderma reesei is an ascomycete fungus wellknown for its ability to secrete high amounts of cellulases and hemicellulases. Due to its saprophytic lifestyle, it can grow on many biomass-derived sugars, including $\mathrm{L}$-arabinose. Although its genome has been predicted to contain roughly 50-100 sugar transporter coding genes
[26-28], less than 10 transporters have been functionally characterized [14, 26, 29-33]. To increase our knowledge of $T$. reesei sugar transportome and to identify novel $\mathrm{L}$-arabinose transporters with potential in biotechnological applications, we set out to investigate L-arabinose transporters from $T$. reesei.

We started our investigation by analyzing a transcriptome data set from a previously published study, which investigated the role of $T$. reesei transcription factors XYR1 and ARA1 on gene expression in the presence of $\mathrm{L}$-arabinose and D-galactose. XYR1 is the master regulator of cellulase and hemicellulase expression in T. reesei along with another transcription factor, ACE3 [34, 35]. On the other hand, ARA1 has been found to regulate the expression of genes involved in L-arabinose and D-galactose metabolism and, additionally some genes involved in pectin metabolism [36]. XYR1 is also involved in the regulation of $\mathrm{L}$-arabinose metabolism, supported by the fact that deletion of both $x y r 1$ and ara1 is required for removal of $T$. reesei growth on L-arabinose [36]. It has been previously observed that the regulatory targets of XYR1 include sugar transporters [34, 37]. Since the genetic and functional orthologs of ARA1 in other fungi regulate the expression of sugar transporters as well, we were interested to see if this is the case also in $T$. reesei [38, 39]. As transporter expression was not analyzed or discussed in the original article about $T$. reesei ARA1 [36], we analyzed the deposited data set to identify sugar transporter genes that were highly expressed on L-arabinose and directly regulated by ARA1, and which thus might play a role in the transport of $\mathrm{L}$-arabinose.

Several known and putative transporters were highly expressed on L-arabinose in an ARA1- or XYR1-dependent manner. To narrow our search, we conducted phylogenetic analysis and investigated the presence of sequence determinants that have been observed to be important regarding pentose utilization [9]. Trire2_104072 was identified as one of the potential L-arabinose transporters. This transporter was previously identified in our institute in 2007 in a study where a $T$. reesei cDNA library was screened for clones that would allow yeast growth on D-xylose, but its kinetics for D-xylose or its ability to transport other sugars were not investigated [14]. Since it was the first D-xylose transporter identified from $T$. reesei, it was named XLT1 (D-xylose transporter 1). After the discovery of this transporter, several other D-xylose transporters have been identified from $T$. reese $i$ $[26,29,32]$. Thus far, no specific L-arabinose transporters have been characterized from T. reesei, although a deletion strain of one of the D-xylose transporters has been reported to have a growth defect on L-arabinose and one D-glucose transporter has been shown to have minor L-arabinose transport activity $[29,40]$. 
Accordingly, we decided to assess Trire2_104072 as a possible L-arabinose transporter. For that end, we chose both yeast and Xenopus model systems for the functional characterization of Trire2_104072. Yeast has been used widely for the characterization of transporters from fungal and plant origin, and it was also used in the original study about Trire2_104072 [14]. The electrophysiological two-electrode voltage clamp (TEVC) method [41], which utilizes oocytes from the African clawed frog Xenopus laevis, has also been used for the characterization of electrogenic sugar transporters (e.g. sugar/proton symporters). Since its use for the characterization of fungal transporters has been rare, we decided to test its suitability for this purpose. This investigation resulted in interesting findings about Trire2_104072, which could serve as a new tool for improving the pentose-utilizing yeast strains.

\section{Results}

Trire2_104072 is highly expressed on L-arabinose in ARA1-dependent manner

To identify potential L-arabinose transporters we analyzed a published transcriptome data set for the expression of sugar transporter genes [36]. In the study by Benocci et al., T. reesei strain QM9414 and its $\Delta x y r 1$, $\Delta$ ara 1 and $\Delta x y r 1 \Delta a r a 1$ deletion mutants were cultured on medium containing L-arabinose or D-galactose as the sole carbon source, and subjected to transcriptome analysis [36]. The set of genes we chose for the analysis included characterized and putative transporter genes from T. reesei (see "Methods"). Expression levels and $\log _{2}$ fold-changes obtained for the chosen transporters are shown in Additional file 1: Figure S1.

From the data it could be seen that several transporters were expressed at high levels on these carbon sources in the parental QM9414 strain (Additional file 1: Figure S1a). When this strain was grown on L-arabinose, the transporter genes with the highest expression levels were the thus far uncharacterized Trire2_82309, D-xylose transporter Trire2_104072 (xlt1) [14], D-glucose/D-xylose transporter Trire2_50894 (str1) [26, 29] and D-glucose facilitator Trire2_47710 (stp1) [30, 42]. Trire2_82309 and Trire2_104072 were downregulated in mutants lacking ARA1, while str1 was downregulated in mutants lacking XYR1 (Additional file 1: Figure S1b). In contrast to these genes whose expression was downregulated in the absence of ARA1 or XYR1, stp1 appeared to be upregulated in the double deletion mutant. Other transporter genes that were differentially expressed in the mutant strains on $\mathrm{L}$-arabinose were the cellobiose/lactose transporter Trire2_3405 (crt1) [30, 33, 43], which was downregulated in the absence of XYR1, and the D-xylose/D-mannose/cellobiose transporter
Trire2_69957 [44], which was regulated by both XYR1 or ARA1 L-arabinose.

Regarding D-galactose, only Trire2_82309 and STP1 were highly expressed on this carbon source (Additional file 1: Figure S1a). Interestingly, STP1 was shown to be able to transport $\mathrm{D}$-galactose and small amounts of L-arabinose in a previous study [40]. As with L-arabinose cultures, Trire2_82309 and Trire2_104072 were downregulated in strains lacking ARA1 (Additional file 1: Figure S1b). Trire2_62380 (str3) [26] and Trire2_22912 (hxt1) [45] were regulated somewhat similarly on both carbon sources, with the former being upregulated in the absence of ARA1 and the latter in the absence of XYR1 (Additional file 1: Figure S1b)

The fact that Trire2_82309 and Trire2_104072 were highly expressed on L-arabinose and downregulated in the mutant lacking ARA1, which is a positive regulator of genes related to L-arabinose metabolism [36], indicates that they might be involved in L-arabinose metabolism of T. reesei. Since Trire2_104072 was highly expressed only on L-arabinose and regulated more strictly by ARA1 on L-arabinose than Trire2_82309, we decided to focus on it in our further analysis.

\section{Trire2_104072 is homologous to L-arabinose transporter from Penicillium chrysogenum}

The gene coding for Trire2_104072 is located on the scaffold 3 of the T. reesei QM6a genome assembly (position 68870-70589) [46]. The same genomic region contains another putative transporter, Trire2_56684 and a putative transcription factor, Trire2_104075. This region is part of the light-regulated cluster described by Stappler et al. [47], which also contains cellulase genes $c b h 2$ and egl2.

A comparison of the sequences of Trire2_104072 from T. reesei QM6a and RUT-C30 (TrireRUTC30_33630) genomes revealed differences between the sequence annotations, as we observed in our previous study with another $T$. reesei membrane transporter CRT1 [33, 46, 48]. The nucleotide sequence found from the QM6a genome annotation is shorter. It contains only 7 exons, while the RUT-C30 version contains one extra exon in the N-terminus. Additionally, the second exon is longer as shown in Fig. 1a. Due to its shorter length, the QM6a version of the protein is predicted by TMHMM [49] to not contain the 12 transmembrane domains (TMD) which are characteristic of major facilitator superfamily (MFS) sugar transporters (Fig. 1b). The RUT-C30 version is estimated to contain 12 TMDs when modelled by CCTOP or Phobius $[50,51]$, but the predicted probabilities for TMDs 3-4 are below 0.5 in the TMHMM prediction (Fig. 1c). The N-terminal intracellular part of the protein is relatively short, while the C-terminal intracellular tail is longer and contains three lysine 
a

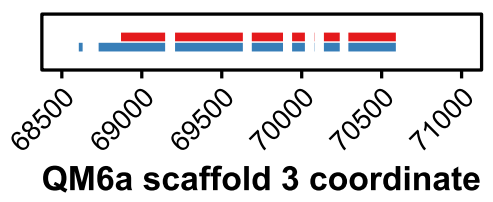

b

MYRIWNIYVLAAFGTIGGMIFGFEISSMSAWIGSEQYLEYFNHPDSTEQGGITAAMSAGSL VGSLLAGWLADRLGRRLAIQIASVDWIVGAVLQCSSQNVAHLVVGRIVSGLAIGITSSQCI VYLSELAPSRIRGRVVGIOOWS IDWGILIMYLISYGCSVSIHRPAAFRIAWGLOAVPGAVL FFSLFFFPESPRWLATKDRWEECHEVLANLHAKGDRNNIEVLAELEEVREAARIAAESKEI GYLGLFAPKMWKRTLVGVSAOIWOOLLGGNVMLYYLVYIFNMAGMSGNTALTSSIIOYVIF LVTTGGVLFVVDRIGRRWLLIVGAIICGVIHFIVGAVMAVYGHHVDSVDGNDILRWQIGGP PAKAIIALCYIFVGVYGVTWADGAWIYCGEVFPLKYRAKGVGLAAAGNWAFNLALAFFVPP AFTNIQWKAYMIFGTFCIAMVFHIYFMYPETVKKSLEEIDVLFEGDIPAWRSASAVSTFDE KVARAKEAGGLEEFSKQADIKHEEKV

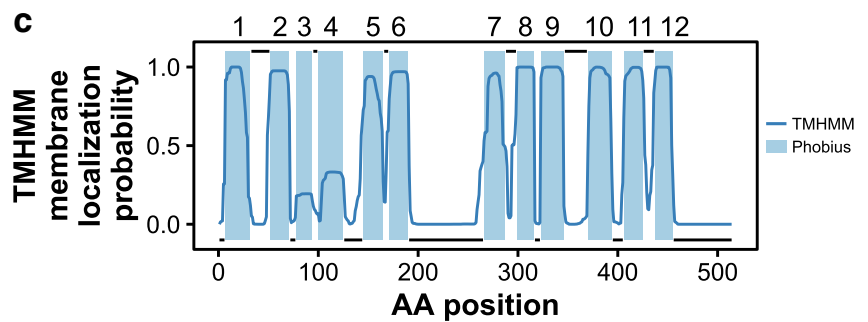

Fig. 1 Sequence, localization and phylogenetic analysis of the L-arabinose transporter Trire2_104072. a Difference between exons in QM6a and RUT-C30 genome annotations of Trire2_104072 b Amino acid sequence of Trire2_104072 colored according to localization predicted by TMHMM (red $=$ intracellular, blue $=$ membrane, purple $=$ membrane with lower probability, green $=$ extracellular). The arrow denotes the start codon at the QM6a genome annotation and the asterisks denote the three predicted medium confidence ubiquitination sites. The proline at position 388 which is mutated in XLT1 is marked with a rectangle $\mathbf{c}$ Plot of the predicted membrane localization. Line shows the predicted membrane localization probability calculated by TMHMM, while the colored segments show transmembrane domains predicted by Phobius. Numbers of the TMDs are indicated on top of the segments. $\mathbf{d}$ Maximum-likelihood tree of Trire2_104072 with other published transporters capable of transporting L-arabinose and L-arabitol (AmLat2). The scale bar indicates number of substitutions per site, and the symbols at the internal nodes present bootstrap support values from 100 runs. The presence of sequence determinants discussed in text is indicated by shaded box. Am, Ambrosiozyma monospora; Nc, Neurospora crassa; Sc, Saccharomyces cerevisiae; At, Arabidopsis thaliana; Pg, Pichia guilliermondii; Ss, Scheffersomyces stipitis; Km, Kluyveromyces marxianus; Mt, Myceliophtora thermophila; Pc, Penicillium chrysogenum residues which were predicted to be ubiquitination sites with medium confidence by the UbPred server [52]. The translation of the cDNA sequence (GenBank accession number AY818402) which was used in the previous report about this transporter is identical to the RUT-C30 version except that it contains a $\mathrm{P} 388 \mathrm{H}$ mutation at the 11th TMD (Fig. 1b) [14]. From now on the version with the P388H mutation will be referred to as XLT1, whereas the version in the RUT-C30 genome annotation will be referred to as Trire2_104072.

Figure 1d shows a phylogenetic alignment of Trire2_104072 with some other transporters which have been reported to be capable of transporting L-arabinose when expressed in yeast. Trire2_104072 groups together with the recently discovered Penicillium chrysogenum L-arabinose transporter AraT (64\% identity with BLASTp) [16]. These two transporters, along with the two other L-arabinose transporters from filamentous fungi (Neurospora crassa LAT-1 and Myceliophtora thermophila LAT-1 [20]) and a transporter from L-arabinose-fermenting yeast (Ambrosiozyma monospora Lat1) $[18,53]$ form their own clade. The three L-arabinose transporters from non-conventional yeasts (Pichia guilliermondii, Scheffersomyces stipitis and Kluyveromyces marxianus $[15,54])$ and the four transporters from plant Arabidopsis thaliana [25] also form their own clades. While all these transporters fall under the same large monophyletic clade, some transporters cluster under different clades. For example, A. monospora Lat2 [18, 53], Trire2_82309 and N. crassa XAT-1 [19] group together outside the previously discussed major clade. Although initially published as an L-arabinose transporter [18], Lat2 was later found to be an L-arabitol and ribitol transporter rather than an L-arabinose transporter [53]. Besides Gal2, which forms its own clade in Fig. 1d, two other S. cerevisiae transporters have been discovered to be able to transport L-arabinose (Hxt9, Hxt10) [15]. However, since they have been shown to be less efficient 
at supporting growth on L-arabinose than Gal2 [15], they were excluded from this analysis.

The prediction of substrate specificities of sugar transporters based on their amino acid sequence has proven to be difficult. However, at least four sequence determinants which are believed to be important for pentose transport and D-glucose inhibition have been identified. To complement the phylogenetic analysis, we surveyed the presence of these motifs from transporters shown in Fig. 1d. Of the four sequence determinants, the first three are located in the first TMD and the fourth in the seventh TMD. The first sequence determinant is the G-G/F-X-X-X-G motif (residues $81-86$ in Gal2) that was discovered to be involved in the ability to transport D-xylose [55]. The transporters with this motif are shown in Fig. 1d, and this part of the alignment is shown in Additional file 1: Figure S2. The phenylalanine residue (position 85 in Gal2) before the last glycine in this motif is conserved in all of these transporters. Mutagenesis of this residue has been reported to improve L-arabinose transport by Gal2 and D-glucose transport by $T$. reesei STP1, but also to reduce D-glucose and D-xylose transport by P. guilliermondii Mgt05196 and D-xylose transport by Escherichia coli XylE [40, 42, 56, 57].

The second sequence determinant is the phenylalanine residue (position 87 in Gal2), which follows the last glycine of the first sequence motif [54]. In transporters that prefer D-xylose as the substrate this phenylalanine is replaced by tyrosine [54]. The transporters in Fig. 1d can be grouped into two clades based on this motif alone, and majority of the transporters have either phenylalanine or tyrosine in this position. This residue is followed by aspartate in all transporters except Trire2_104072, which has glutamate in this position. Mutation of this residue from aspartate to alanine was found to abolish D-glucose and D-xylose transport in Trire2_63966 [32]. The third sequence determinant, which has been shown to play a role in specificity for L-arabinose, is the tyrosine at position 89 in Gal2 [58]. Mutation of this residue to isoleucine altered the $K_{\mathrm{m}}$ of Gal2 for L-arabinose from 335 to $99 \mathrm{mM}$ and lowered the ratio of $K_{\mathrm{m}}$ values of L-arabinose and D-glucose tenfold from 176 to 15 [58].

The fourth sequence determinant is the asparagine at position 376 in S. cerevisiae Gal2 (TMD 7), which has been implicated to be important for D-glucose inhibition [9]. Asparagine is replaced by phenylalanine in all transporters which possess the second motif (F 87), except the two which still have asparagine in this position (S. stipitis AraT and K. marxianus Axt1). Mutation of this residue from asparagine to phenylalanine was found to abolish D-glucose transport and decrease $K_{\mathrm{m}}$ for D-xylose in Gal2 [59]. Other studies have also shown significance of this residue for different transporters [32, 40, 56]. Besides sequence determinants in TMDs 1 and 7, TMD 6 also contains a motif (YFFYY in Gal2) which has been shown to be important for pentose transport [32, 40, 56, 57, 60]. Interestingly, all of the transporters which possess the second sequence determinant (F87) also have valine at the first position of this motif (Additional file 1: Figure S2). The proline residue which has been mutated to histidine in XLT1 (position 452 at Gal2) is conserved in most of the transporters, and it is not replaced by histidine in any of them. Of these transporters, only N. crassa LAT1, M. thermophila LAT-1 and Trire2_104072 possess all of the sequence determinants shown in Fig. 1d. The presence of important sequence determinants and homology to a specific L-arabinose transporter further suggested that Trire2_104072 might function as a L-arabinose transporter.

\section{Functional analysis of Trire2_104072 with electrophysiological methods}

We performed functional characterization of Trire2_104072 with the electrophysiological TEVC method which utilizes $X$. laevis oocytes. The gene was ligated into a $X$. laevis expression vector, which allowed us to in vitro transcribe mRNA which was then injected into the oocytes. Since the QM6a version did not possess the 12 TMDs typical of MFS transporters, we used the RUT-C30 version of the gene for the functional analysis. The oocytes injected with Trire2_104072 mRNA were tested for transport activity of different sugars. In contrast to oocytes injected with water as a control (data not shown), oocytes injected with Trire2_104072 mRNA transported D-xylose, as expected, and also L-arabinose and D-glucose, as witnessed by analysis of the current traces (Fig. 2a). The traces also indicated that $\mathrm{L}$-arabinose induces higher currents than D-xylose or D-glucose, suggesting that this sugar is transported with the highest rate. The currents induced by $\mathrm{D}$-glucose were lower than those for L-arabinose and D-xylose. To further study the selectivity of Trire2_104072, we measured current as a function of voltage (I-V curve) in the presence of different sugars (Fig. 2b). Significantly higher negative currents were seen for L-arabinose (about $-350 \mathrm{nA}$ at $-50 \mathrm{mV}$ ) as shown in Fig. 2c, but the currents for other sugars, including D-xylose, were small at this voltage. No sugarinduced currents were seen in the I-V curves obtained from water-injected oocytes (Fig. 2c). The presence of sugar-induced currents indicates that the transport was electrogenic, and that Trire2_104072 functions as a sugar/proton symporter.

Kinetic studies revealed that Trire2_104072 is a high-affinity transporter for L-arabinose with $K_{\mathrm{m}}$ of $0.207 \pm 0.079 \mathrm{mM}$ (mean \pm standard deviation, $n=3$ ) at pH 5.5 and $-50 \mathrm{mV}$, as shown in Fig. 3a. Regarding 

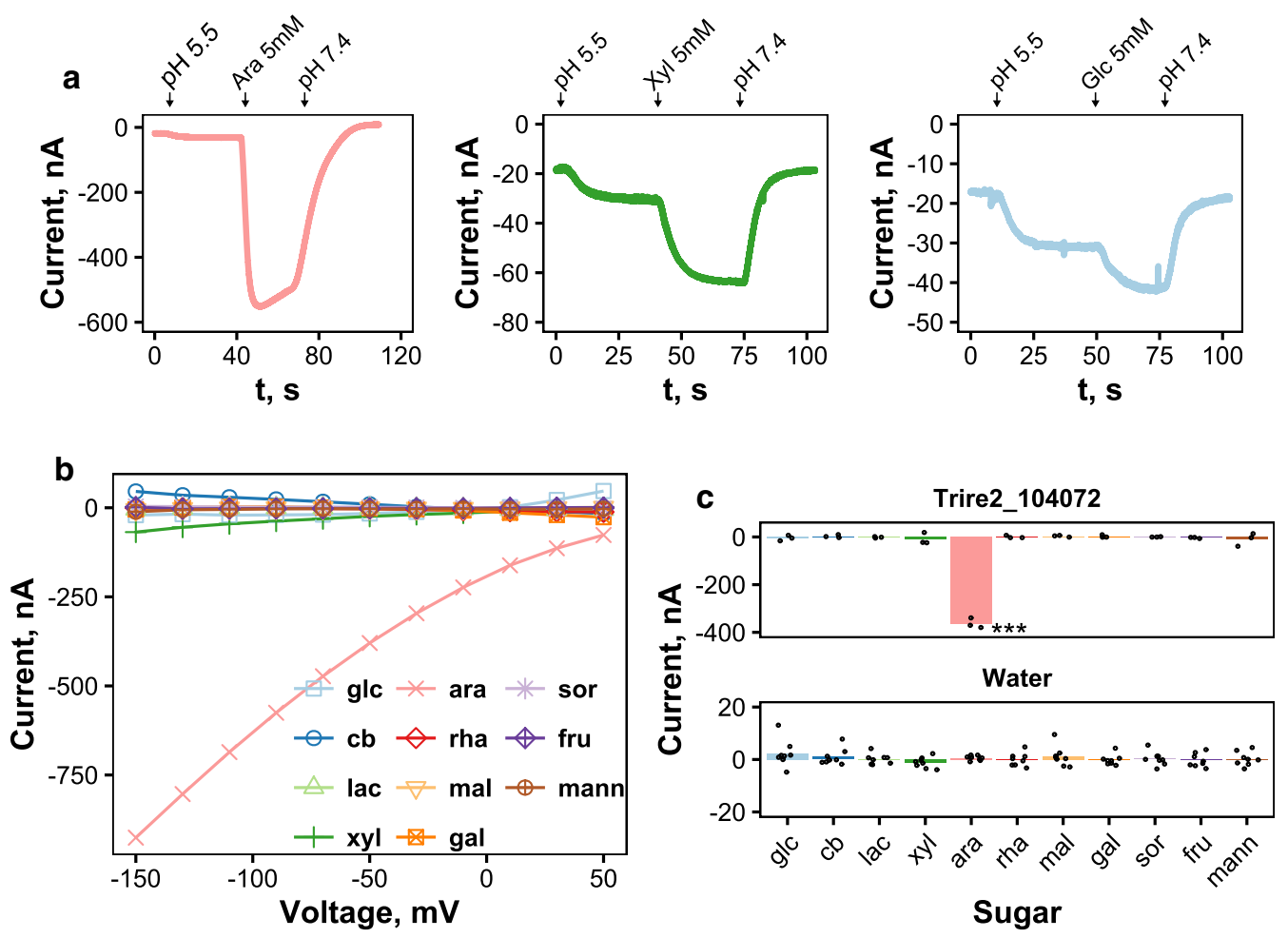

Fig. 2 Electrophysiology studies of Trire2_104072. a Current traces from a representative TEVC experiment where Trire2_104072-expressing oocyte clamped to - $50 \mathrm{mV}$ was perfused with $5 \mathrm{mM}$-arabinose (left), $5 \mathrm{mM}$ D-xylose (middle) or $5 \mathrm{mM}$ D-glucose (right) b I-V curves from a TEVC experiment where a Trire2_104072-expressing oocyte was perfused with different sugar solutions with $5 \mathrm{mM}$ concentration and the sugar-induced currents were measured at different clamping voltages. Results from a representative experiment are shown. glc, D-glucose; cb, cellobiose; lac, lactose; xyl, D-xylose; ara, L-arabinose; rha, L-rhamnose; mal, maltose; gal, D-galactose; sor, L-sorbose; fru, D-fructose; mann, D-mannose. c Selectivity plot of oocytes injected with water or Trire2_104072 mRNA. Currents induced by different sugars at $-50 \mathrm{mV}$ are shown. Points present results from different oocytes and bars present their average. Significance was estimated with ANOVA and Tukey's test $\left.{ }^{* * *}: p<0.005\right)$

D-xylose, it is a low-affinity transporter with $K_{\mathrm{m}}$ of $9.16 \pm 3.35 \mathrm{mM}$ in the same conditions (Fig. 3b). The $I_{\max }$ values for L-arabinose and D-xylose were $-355 \pm 72$ $\mathrm{nA}$ and $-72.3 \pm 22.3 \mathrm{nA}$ at $\mathrm{pH} 5.5$ and $-50 \mathrm{mV}$. Current as a function of proton concentration followed Hill kinetics with $K_{0.5}$ of $68.9 \pm 55.1 \mathrm{nM}(\mathrm{pH} 7.3 \pm 0.47)$ at $-50 \mathrm{mV}$ when determined in the presence of $5 \mathrm{mM}$ L-arabinose (Fig. 3c). This high affinity for protons causes Trire2_104072 to retain about $25 \%$ of its maximum transport activity even at $\mathrm{pH} 9$ (Fig. 3d). The affinity of Trire2_104072 for protons is somewhat similar to that observed for $U$. maydis sucrose transporter $\operatorname{Srt1}\left(K_{0.5} \mathrm{pH}\right.$ 7.3 for Trire2_104072, $K_{\mathrm{m}} \mathrm{pH} 7.7$ for Srt1) [61].

Analysis of the kinetics at different voltages revealed that higher transport rates are obtained at lower voltages (Additional file 1: Figure S3a-c). There were no significant differences in the voltage-dependence of $I_{\max }$ between the substrates (Additional file 1: Figure S3d). Regarding the dependence of $K_{\mathrm{m}}$ value on voltage, opposite trends were seen for L-arabinose and protons, although variation between the experiments was high
(Additional file 1: Figure S3e-f). The Hill coefficient of the $\mathrm{pH}$-dependence increased as the voltage became more depolarized (Additional file 1: Figure S3g). The values obtained for the Hill coefficient were below 1, which indicates negative cooperativity.

The shape of the curves during I-V measurements suggested that this transporter exhibits pre-steady state currents (Additional file 1: Figure S4a). Pre-steady state currents are found only from certain symporters, and they are thought to be caused by the movements of the empty transporter in response to voltage jumps [62, 63]. The charge movements were extracted from the currents and they were found to be inhibited by the presence of L-arabinose (Additional file 1: Figure S4b). To study this phenomenon further, we measured the charge movements at different $\mathrm{pH}$ values in the absence of L-arabinose. Charge movements increased with proton concentration until $\mathrm{pH}$ 6.5-7, after which they started to decrease again (Additional file 1: Figure S4c-d). The dependence of $\mathrm{V}_{0.5}$ and $\mathrm{Q}_{\max }$ on $\mathrm{pH}$ followed a similar trend between the two tested oocytes, although the 

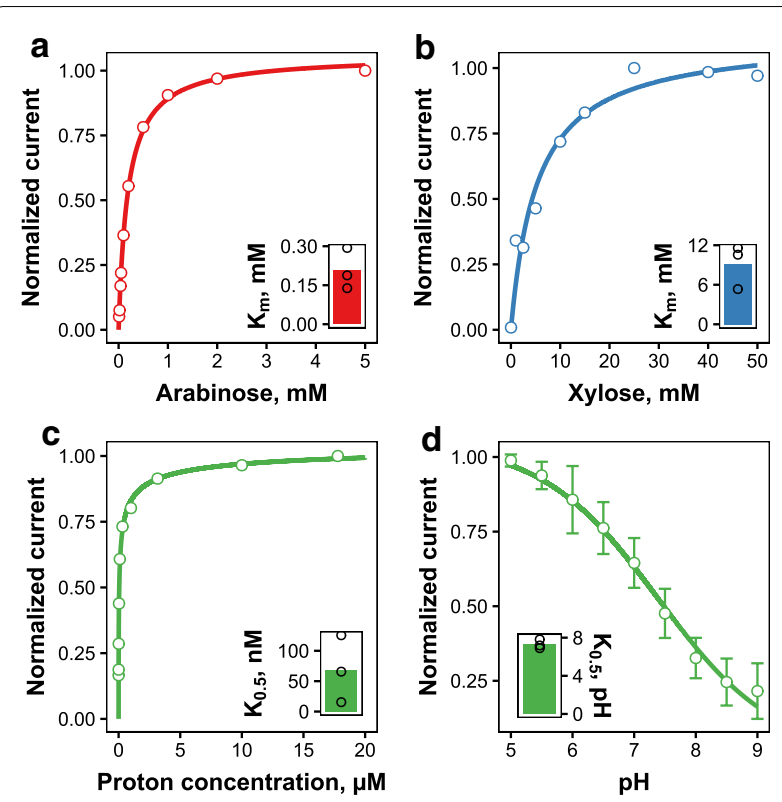

Fig. 3 Kinetics determination of Trire2_104072 with

electrophysiology. a-c Representative experiments of the kinetics studies for L-arabinose (a), D-xylose (b) or proton concentration (c) at $-50 \mathrm{mV}$. Kinetics for proton concentration were determined in the presence of $5 \mathrm{mM}$ L-arabinose. The values were normalized to the lowest current obtained for each sugar at $-50 \mathrm{mV}$. Insets show the predicted $K_{\mathrm{m}}(\mathbf{a}, \mathbf{b})$ or $K_{0.5}(\mathbf{c})$ values (points) and their mean (bar) from three different oocytes. Line shows the Michaelis-Menten $(\mathbf{a}, \mathbf{b})$ or Hill (c) kinetics prediction. d Normalized current as a function of $\mathrm{pH}$ at $-50 \mathrm{mV}$. Points and error bars present mean and standard deviation between currents obtained from three different oocytes, and line shows the Hill kinetics prediction. Inset shows the predicted $K_{0.5}$ values as $\mathrm{pH}$, with presentation as in $\mathbf{a}-\mathbf{c}$

magnitudes were different (Additional file 1: Figure S4e-f). The maximal charge transfer can be used for the calculation of transporter turnover rate, indicating the number of sugar molecules transported per unit time. The turnover numbers for $\mathrm{L}$-arabinose and $\mathrm{D}$-xylose were $60.2 \pm 16.7 \mathrm{~s}^{-1}$ and $12.3 \pm 2.85 \mathrm{~s}^{-1}$ (mean \pm standard deviation, $n=3)$ at $\mathrm{pH} 5.5$. Similar values have been obtained for other transporters, e.g. human SGLT1 (28 $\left.\mathrm{s}^{-1}\right)$ and $A$. thaliana STP1 $\left(59 \mathrm{~s}^{-1}\right)[64,65]$.

\section{Characterization of Trire2_104072 in yeast}

We also performed experiments with Trire2_104072 in yeast to complement the electrophysiological studies. We included XLT1 (Trire2_104072 $2^{\mathrm{P} 388 \mathrm{H}}$ ) in the analysis, since the mutation of proline to histidine can be considered as a radical replacement, which could affect the transport properties. The ability of the resulting strains to uptake L-arabinose was tested with uptake experiments with ${ }^{14} \mathrm{C}$-labeled L-arabinose. The L-arabinose uptake rate was clearly increased by the expression of Trire2_104072 or XLT1 in comparison with the control strain which was transformed with the empty pFL60 plasmid (Fig. 4a). The strain expressing Trire2_104072 had about twofold higher transport rate than the strain expressing XLT1. To test if the uptake of L-arabinose was inhibited by other sugars, we measured L-arabinose uptake in the presence of other sugars in a competition assay where the competing sugar was present in fivefold excess (Fig. 4b). No inhibition was seen with D-glucose $(0 \pm 8.2 \%$, mean \pm standard deviation), but D-xylose appeared to be slightly inhibitory $(10.9 \pm 6.3 \%)$. As expected, L-arabinose itself inhibited the transport. Similar inhibition percentages were obtained for XLT1 (D-glucose: $4.5 \pm 17.6 \%$, D-xylose: $13.4 \pm 7.9 \%$ ), which suggests that the $\mathrm{P} 388 \mathrm{H}$ mutation did not affect the substrate specificity. Analysis of L-arabinose transport kinetics in yeast revealed somewhat similar results to the Xenopus results, as shown in Fig. 4c. $V_{\max }$ and $K_{\mathrm{m}}$ values of $1.49 \pm 0.07 \mathrm{nmol}$
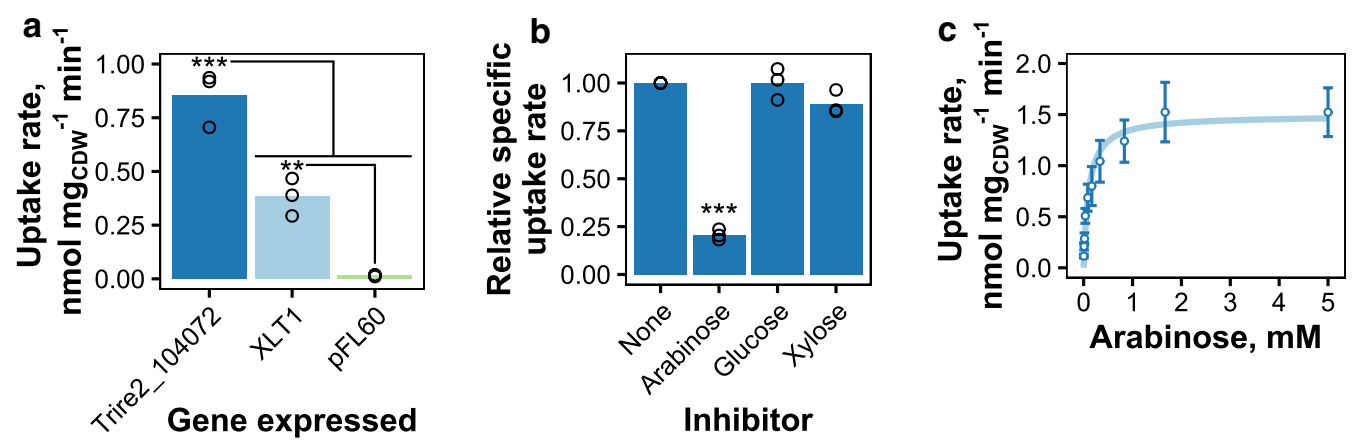

Fig. 4 L-arabinose uptake studies with Trire2_104072 expressed in yeast. a Comparison of L-arabinose uptake rates of yeast strains transformed with Trire2_104072, XLT1 (Trire2_104072 ${ }^{\mathrm{P} 88 \mathrm{H}}$ ) expression plasmids or with the control plasmid. Significance was estimated with ANOVA and Tukey's test $\left(*^{* *}: p<0.01,{ }^{* * *}: p<0.005\right)$. Arabinose concentration was $0.167 \mathrm{mM}$. Points present results from three individual experiments and bars their average. b Inhibition of L-arabinose transport of Trire2_104072. Arabinose concentration was $0.167 \mathrm{mM}$ and the concentration of the inhibiting sugar was 0.833 mM. Presentation and statistics as in panel a. c Kinetics of L-arabinose uptake of Trire2_104072 at pH 6.5. Points are average values from three independent experiments and the error bars present the standard deviation between them. Line presents the Michaelis-Menten kinetics prediction 
$\mathrm{mg}_{\mathrm{CDW}}{ }^{-1} \mathrm{~min}^{-1}$ (mean \pm std. error of the prediction) and $0.102 \pm 0.020 \mathrm{mM}$ were obtained at $\mathrm{pH}$ 6.5. The $K_{\mathrm{m}}$ value obtained in yeast is about half of that obtained in oocytes.

We then compared these two transporters to few other published L-arabinose transporters: $P$. chrysogenum AraT, N. crassa LAT-1, P. guilliermondii Axt1, A. thaliana STP7, Trire2_82309 and S. cerevisiae Gal2. All genes were expressed from similar expression vectors $(2 \mu \mathrm{m}$, $U R A 3$ selection) and with the $P G K 1$ promoter except for $G A L 2$, which was expressed with the $A D H 1$ promoter. All genes were codon-optimized for yeast expression, except A. monospora LAT1 and A. thaliana STP7, for which CDNA sequences were used. Figure 5 a shows the amount of L-arabinose uptaken by the yeast cell suspensions as a function of time with $0.167 \mathrm{mM} \mathrm{L}$-arabinose. Yeast strains expressing Trire2_104072, XLT1 and P. chrysogenum AraT were able to uptake higher amounts of $\mathrm{L}$-arabinose when compared to the other strains. Since Trire2_104072 has high affinity for both L-arabinose and protons, we also did experiments with higher $\mathrm{L}$-arabinose concentration and lower $\mathrm{pH}$, which also reflect actual fermentation conditions better. Figure $5 \mathrm{~b}$ shows results from both conditions, and from the figure it can be seen that the strains which expressed Trire2_104072, XLT1 or $P$. chrysogenum AraT had significantly higher L-arabinose uptake rates than the control strain (pFL60) in the both tested conditions $(p<0.005)$. The strain expressing A. thaliana STP7 had also significantly higher uptake in the condition with higher L-arabinose concentration and lower $\mathrm{pH}(p<0.01)$. This result is in agreement with its previously determined $\mathrm{pH}$ optimum of 4 [25]. A. monospora Lat 1 also had slightly higher uptake rate in this condition, but it was not significantly higher than the uptake rate of the control strain. In both conditions, the strain expressing Trire2_104072 had significantly higher uptake rate $(p<0.005)$ than the other strains which had significant uptake rates in relation to the control strain.

\section{Trire2_104072 is not essential for growth of $T$. reesei on L-arabinose}

Given our findings, we were interested in the role of Trire2_104072 during growth of T. reesei on L-arabinose. The arabinolytic system of $T$. reesei is thought to be induced by either L-arabinose or its downstream metabolite arabitol, which is formed intracellularly from $\mathrm{L}$-arabinose via D-xylose reductase XYL1 [66]. We hypothesized that the induction of the arabinolytic system might be disrupted in the absence of Trire2_104072 due to inducer exclusion.

To test our hypothesis, the gene coding for Trire2_104072 was deleted from T. reesei strain M44. The deletion was confirmed with PCR, which verified the correct integration of the deletion cassette and the absence of Trire2_104072 open reading frame (data not shown). Additionally, we confirmed the absence of Trire2_104072 expression with RT-qPCR. For this, the parental and deletion strains were first cultivated on minimal medium
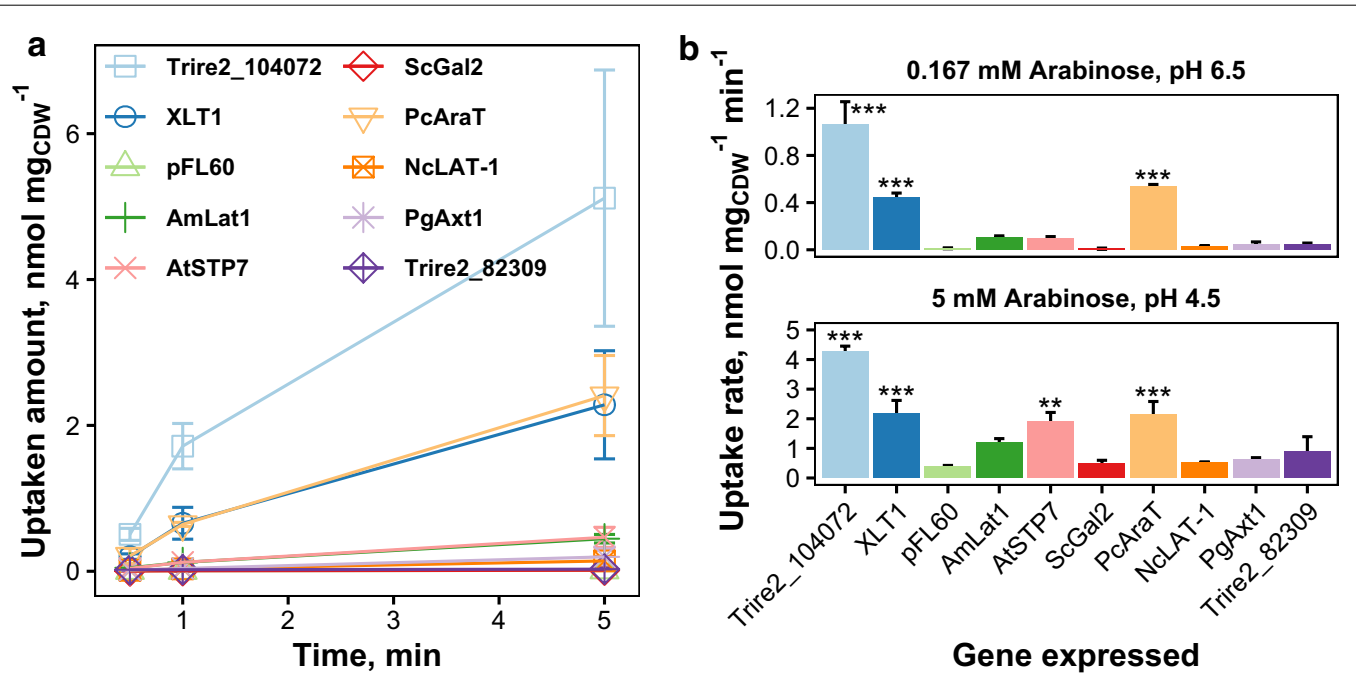

Fig. 5 Comparison of L-arabinose uptake by different transporters when expressed in yeast. a Amount of L-arabinose uptaken by yeast strains expressing different L-arabinose transporters in assay with $0.167 \mathrm{mM} \mathrm{L}$-arabinose at $\mathrm{pH}$ 6.5. Error bars present standard deviation between 2-3 independent experiments. $\mathbf{b}$ L-arabinose uptake rates at two different conditions: $0.167 \mathrm{mM}$ L-arabinose at pH 6.5 (top) and 5 mM L-arabinose at pH 4.5 (bottom). Error bars in present standard deviation between two independent experiments with two separate transformants. Strains with significantly higher uptake rate than control ( $p F L 60)$ are indicated. Significance was estimated with ANOVA and Tukey's test $\left(* * *: p<0.005,{ }^{* *}\right.$ : $p<0.01)$ 
with sorbitol as the carbon source. Sorbitol can be considered a neutral carbon source for $T$. reesei, as it does neither repress or induce cellulase or hemicellulase production [67]. After sufficient biomass had been reached, either D-glucose or L-arabinose was added to $1 \%$ concentration before harvesting the mycelium $6 \mathrm{~h}$ later. As shown in Additional file 1: Figure S4a, Trire2_104072 expression was highly induced on $\mathrm{L}$-arabinose medium in the parental strain, whereas its expression was hardly detected from the deletion strain. These expression values correspond to a $\log _{2}$ fold-change of $8.12 \pm 0.23$ in the parental strain between L-arabinose and D-glucose, and to a $\log _{2}$ fold-change of $-8.07 \pm 0.83$ between the deletion and parental strains on $\mathrm{L}$-arabinose (mean \pm standard deviation, $n=2$ ). To see if regulation by ARA1 was affected, we analyzed the expression of the gene coding for extracellular $\beta$-galactosidase, bga1, whose expression on L-arabinose is regulated mainly by ARA1 [36]. However, no significant differences were seen in the expression of this gene, as it was induced about 3-4 $\log _{2}$ fold in both strains when comparing between $\mathrm{L}$-arabinose and D-glucose (Additional file 1: Figure S5a).

To further study the effects of the deletion, we compared total protein secretion and growth of the deletion and wild-type strains. Despite the absence of Trire2_104072, no differences were seen in protein production on minimal medium with $1 \% \mathrm{~L}$-arabinose as the carbon source, or on spent grain extract (SGE) medium with $4 \%$ lactose as the carbon source (data not shown). Spent grain extract has high arabinoxylan content, and has been used by us as an additional inducer for cellulase and hemicellulase production $[68,69]$. When grown on plates, the deletion strain did not have an altered phenotype on minimal medium with $1 \% \mathrm{~L}$-arabinose (data not shown). In liquid cultures, the parental and deletion strains grew similarly in minimal medium with L-arabinose, D-galactose and D-xylose in 1\% concentration (Additional file 1: Figure S5b). Small growth improvement, mostly due to shorter lag time, was seen with $1 \%$ $\mathrm{D}$-glucose as the carbon source, but we didn't investigate this further as the effect was small (Additional file 1: Figure S5b).

Since these typically used sugar concentrations are substantially higher $(55.5 \mathrm{mM}$ for hexoses, $66.6 \mathrm{mM}$ for pentoses) than the $K_{\mathrm{m}}$ value of Trire2_104072 for L-arabinose $(0.1-0.2 \mathrm{mM})$, we repeated the experiment with $0.01 \%$ concentration of the same sugars. This concentration corresponds to $0.555 \mathrm{mM}$ for hexoses D-glucose and D-galactose, and to $0.666 \mathrm{mM}$ for pentoses D-xylose and $\mathrm{L}$-arabinose. In this concentration, we witnessed a growth defect for the deletion strain on L-arabinose, while growth on the other carbon sources was similar to that observed at $1 \%$ concentration (Additional file 1:
Figure S5c). Similar experiments performed at L-arabinose concentrations ranging from 0.01 to $0.2 \%$ showed that this growth defect is observed at concentrations at or below $0.05 \%$, which corresponds to $3.33 \mathrm{mM}$ (Additional file 1: Figure S5d). These experiments proved that Trire2_104072 functions as a high-affinity L-arabinose transporter in $T$. reesei, and that it is required for growth only at a narrow concentration range.

\section{Discussion}

Although sugar transporters are structurally conserved, their low sequence similarity does not allow the judgement of substrate specificity based on sequence alone. Transcriptome analyses have proven to be useful for the identification of fungal sugar transporters. Of the previously published transporters discussed in this study, PcAraT, NcLAT-1, PgAXT1 and NcXAT-1 were identified with transcriptomic techniques [16, 19, 54, 70]. Transporter identification has been further facilitated by the identification of several fungal transcription factors which regulate gene expression only on specific carbon sources [71]. ARA1, which regulates L-arabinose and D-galactose metabolism in $T$. reesei, is an example of such a transcription factor [36].

Since XYR1 and multiple other transcription factors in T. reesei have been shown to regulate the expression of sugar transporters, we hypothesized that the same would be true for ARA1. Of the four genes (Trire2_104072, Trire2_82309, Trire2_50894/str1, Trire2_47710/stp1) with the highest expression on L-arabinose, two were downregulated in the $\Delta$ ara1 mutant (Trire2_104072, Trire2_82309) and one in the $\Delta x y r 1$ mutant (str1). We noted that these genes were significantly downregulated in similar manner in $\Delta a r a 1$ and $\Delta x y r 1$ mutants of QM9414 in a previous study [72]. In this study, gene expression upon growth with corn stover or soybean hulls as the carbon source was analyzed. After $4 \mathrm{~h}$ of growth on corn stover, Trire2_104072 and Trire2_82309 were downregulated in $\triangle a r a 1$ strain and STR1 in $\Delta x y r 1$ strain (see Additional file 4 in Ref. [72]). Similar results were also obtained with soybean hulls as the carbon source, except that STR1 was also downregulated in the a ara1 mutant. However, the downregulation was less severe in this strain than in the $\Delta x y r 1$ mutant $\left(\log _{2}\right.$ foldchanges of -7.8 vs -2.1 when compared between the $\Delta x y r 1$ or $\Delta$ ara 1 mutants, respectively, and the parental strain at $4 \mathrm{~h}$ timepoint).

Since we were interested in specific L-arabinose transporters, we focused our studies on the two transporters regulated solely by ARA1, as both STR1 and STP1 have been shown to transport D-glucose [26, 30, 42]. STR1 also transports D-xylose, but with low affinity compared to D-glucose [26]. Despite its high affinity for D-glucose, 
it has been suggested to be involved in D-xylose and $\mathrm{L}$-arabinose transport as its deletion leads to a growth defect on these sugars [26, 29].

In contrast to the other genes that were highly expressed on L-arabinose, the fourth gene (Trire2_47710/stp1) appeared to be upregulated in the double deletion mutant. The double deletion mutant failed to grow on L-arabinose [36], and therefore this could potentially be part of the starvation response. Upregulation during starvation has been been observed for STP1 previously in comparison to Avicel-grown cultures, and its homolog HGT-1 from $N$. crassa is also upregulated during starvation [30, 73]. Similar upregulation in the double deletion mutant was observed for another transporter, Trire2_121482/STR2, whose expression was discovered to be highest in starvation conditions in a separate study [26]. However, neither stp1 or str 2 were upregulated in $\Delta a r a 1$ or $\Delta x y r 1 \Delta a r a 1$ mutants when grown on D-galactose, although these mutants were also unable grow on this carbon source. In this case the metabolism of D-galactose was probably more affected rather than its transport, since STP1 itself has been shown to be able to transport $\mathrm{D}$-galactose and was expressed at high levels [40].

After excluding STR1 and STP1 from our search for specific $\mathrm{L}$-arabinose transporters from $T$. reesei, we were left with Trire2_104072 and Trire2_82309. Trire2_82309 was further excluded based on the phylogenetic and sequence analyses. Our hypothesis on Trire2_104072 was verified to be correct by the TEVC analysis, where we observed L-arabinose transport with high affinity. Both Trire2_104072 and its P388H-mutant XLT1 also functioned as L-arabinose transporters in yeast. Expression of Trire2_104072 resulted in higher uptake rate, but this difference could be explained by other reasons than the $\mathrm{P} 388 \mathrm{H}$ mutation (e.g. the lack of codon optimization for XLT1). Regarding L-arabinose uptake kinetics, Trire2_104072 appears to be similar to P. chrysogenum AraT, A. thaliana STP7 and P. guilliermondii Axt1, as shown in Table 1 . All of them are high-affinity L-arabinose symporters with $K_{\mathrm{m}}$ values in range of $0.1-0.3$ $\mathrm{mM}$. Interestingly, transporters with even higher affinities have been identified (A. monospora Lat1, A. thaliana STP4 and STP14). Since the details regarding the used expression systems (strains, expression constructs, fusion tags) and assay conditions (e.g. pH) vary between the published studies, direct comparison of $V_{\max }$ values is not possible. In one report, the inclusion of fluorescent proteins or adenylate kinase as a fusion partner increased the transport rate 3-20 fold, although in some studies no differences, or a difference in the opposite direction, were seen between tagged and non-tagged transporters [53, $74,75]$.
Several of the transporters listed in Table 1 were tested for L-arabinose uptake in this study. Uptake was tested in two different conditions, since we were concerned that low substrate concentration and high $\mathrm{pH}$ would be favorable for Trire2_104072 due to its high affinity for L-arabinose and protons. However, it outperformed the other transporters in both tested conditions. The lack of L-arabinose transport by Trire2_82309 would support its involvement in pentitol transport, as hypothesized on the basis of the phylogenetic analysis, or in the transport of some other sugar. Based on the kinetics values listed in Table 1, P. chrysogenum AraT, N. crassa LAT-1 and P. guilliermondii Axt1 should have been able to uptake L-arabinose at a higher rate than Trire2_104072, but this was not the case. In the original publication, $N$. crassa LAT-1 was tagged with GFP [20], which might increase the transport rate as mentioned before [53]. The lat-1 sequence that was expressed in this study was also codon optimized, as opposed to the cDNA sequence used in the original publication [20]. This was also the case for $P$. chrysogenum araT and $P$. guilliermondii AXT1 $[16,54]$. The sequences of $A$. thaliana STP7 and A. monospora $L A T 1$ were identical to those used in the original publications, but $A$. thaliana STP7 was under the control of different promoter $[18,25]$. These results underline that the kinetics values reported from yeast uptake experiments are strongly affected by expression and assay conditions.

Besides the effect of assay and expression conditions on the $V_{\max }$ value, it has also been reported that $\mathrm{pH}$ can affect the $K_{\mathrm{m}}$ value of transporters $[61,76]$. Additionally, the membrane potential is also affected by $\mathrm{pH}$ and this in turn can also affect the measurements. Membrane potential cannot be controlled in yeast uptake experiments, but it is well controlled by TEVC in the oocyte electrophysiological studies. Oocytes are clamped at a specific voltage, which is not affected by $\mathrm{pH}$. The downside of the TEVC method is that it can only be used with electrogenic transport proteins, which move net charges, e.g. sugar/proton symporters and ion channels. The sugar/ proton symport mechanism allows transport of sugars against their concentration gradient at the expense of energy that is consumed by pumping protons across the cell membrane. This enables the saturation of the intracellular metabolic enzymes with their substrates, even though the extracellular concentration would be low [9]. This can be beneficial in the natural environment of saprophytic fungi, where the concentration of sugars is low, and it could explain why many of the fungal sugar transporters appear to be symporters, while most of the yeast sugar transporters are passive facilitators [45, 77]. Majority of the transporters listed in Table 1 use proton symport as their mechanism and thus they could be studied with electrophysiology. 
Table 1 Kinetic parameters of published L-arabinose transporters. $V_{\max }$ values are reported as nmol min ${ }^{-1} \mathrm{mg}^{-1}$ and $K_{\mathrm{m}}$ values as mM. $\mathrm{H}^{+}$indicates proton/sugar symport mechanism

\begin{tabular}{|c|c|c|c|c|c|c|c|c|}
\hline \multirow[t]{2}{*}{ Organism } & \multirow[t]{2}{*}{ Protein } & \multirow[t]{2}{*}{$\mathbf{H}^{+}$} & \multicolumn{2}{|l|}{ Arabinose } & \multicolumn{3}{|c|}{ Other sugars } & \multirow[t]{2}{*}{ References } \\
\hline & & & $V_{\max }$ & $K_{\mathrm{m}}$ & Sugar & $V_{\max }$ & $K_{\mathrm{m}}$ & \\
\hline A. monospora & Lat $1^{a}$ & n.d. & 1.1 & 0.03 & & & & [53] \\
\hline \multirow[t]{4}{*}{ A. thaliana } & $\mathrm{STP} 2^{\mathrm{b}}$ & $x$ & $0.6 \pm 0.08$ & $4.5 \pm 2.2$ & $\mathrm{Gal}^{\mathrm{d}}$ & & 0.05 & {$[15,104]$} \\
\hline & STP4 ${ }^{C}$ & $x$ & $1895 \pm 142$ & $0.033 \pm 0.005$ & $G c^{d}$ & & 0.015 & {$[25,105]$} \\
\hline & STP7C & $x$ & $230 \pm 13$ & $0.29 \pm 0.03$ & Gal & & 28 & {$[25]$} \\
\hline & STP14 & $x$ & $220 \pm 17$ & $0.018 \pm 0.004$ & Gal & 68.33 & 0.529 & {$[25,106]$} \\
\hline K. marxianus & Axt1 & & $57 \pm 6$ & $263 \pm 57$ & $\mathrm{xyl}$ & $3.8 \pm 0.02$ & $27 \pm 3$ & {$[54]$} \\
\hline M. thermophila & LAT- $^{\mathrm{e}}$ & $x$ & $171.5 \pm 5.8$ & $29.4 \pm 3.6$ & & & & [20] \\
\hline \multirow[t]{2}{*}{ N. crassa } & XAT-1 & n.d. & $1.1 \pm 0.2$ & $61.93 \pm 17.68$ & Xyl & $0.9 \pm 0.06$ & $18.17 \pm 3.23$ & [19] \\
\hline & LAT- $^{\mathrm{e}}$ & $x$ & $1945 \pm 50$ & $58.12 \pm 4.06$ & & & & {$[20]$} \\
\hline P. chrysogenum & AraT & $x$ & $5.3 \pm 0.2$ & $0.13 \pm 0.03$ & & & & [16] \\
\hline P. guilliermondii & Axt1 & $x$ & $18 \pm 0.8$ & $0.13 \pm 0.04$ & Xyl & $8.7 \pm 0.3$ & $65 \pm 8$ & [54] \\
\hline \multirow[t]{3}{*}{ S. cerevisiae } & Gal2 & & $341 \pm 7$ & $371 \pm 19$ & Gal & 76 & 25 & [54] \\
\hline & & & $75 \pm 5.2$ & $335 \pm 21$ & Glc & $27.2 \pm 0.9$ & $1.5 \pm 0.2$ & {$[16,59]$} \\
\hline & & & $2.2 \pm 0.26$ & $57 \pm 11$ & Xyl & $91.3 \pm 3.2$ & $225.6 \pm 15.8$ & {$[15,59]$} \\
\hline S. stipitis & AraT & n.d. & $0.4 \pm 0.06$ & $3.8 \pm 1.7$ & & & & {$[15]$} \\
\hline \multirow[t]{2}{*}{ T.reesei } & $104072^{f}$ & $x$ & $1.49 \pm 0.07$ & $0.102 \pm 0.020$ & & & & This study \\
\hline & $104072^{g}$ & $x$ & & $0.207 \pm 0.079$ & $\left.x y\right|^{9}$ & & $9.16 \pm 3.35$ & This study \\
\hline
\end{tabular}

n.d. not determined

${ }^{\mathrm{a}}$ mCherry fusion protein was used

${ }^{\mathrm{b}}$ protein contained HA epitope

${ }^{c} V_{\text {max }}$ as $\mathrm{nmol} \mathrm{min}^{-1} \mathrm{~mL}^{-1}$

${ }^{d}$ Expressed in Schizosaccharomyces pombe

e GFP fusion protein was used

${ }^{f}$ Determined in yeast

${ }^{9}$ Determined in oocytes

Some of the transporters listed in Table 1 have higher affinity for some other sugar than L-arabinose, suggesting that $\mathrm{L}$-arabinose is not their primary substrate. Additionally, most of the listed transporters have been reported to be able to transport other sugars than L-arabinose, with the exceptions of $P$. chrysogenum AraT and M. thermophila LAT-1 (see references in Table 1). It has been reported that the ability to transport $\mathrm{L}$-arabinose is common among the A. thaliana STP sugar transporters: of the 13 functional members of the STP family, all but one had some L-arabinose transport activity [25]. Of the T. reesei transporters, Trire2_47710 (STP1) has also been shown to have minor L-arabinose uptake activity, although L-arabinose was only slightly inhibitory to D-glucose transport and thus is expected to be only a low affinity substrate for this transporter [40, 42]. These results indicate that the ability to transport L-arabinose might be widespread among MFS monosaccharide transporters, and kinetic studies are needed to investigate which of the transporters are actually specific for $\mathrm{L}$-arabinose.
Regarding the inhibition characteristics of the transporters, the low inhibition of L-arabinose transport by D-glucose observed for Trire2_104072 is remarkable (Table 2). As mentioned previously, inhibition of L-arabinose and D-xylose transport by D-glucose is a problem with yeast pentose utilization [9]. Although the inhibition characteristics of Gal2 have been improved by mutations of the previously mentioned residue (N376), the mutated variants suffer from $20-30 \%$ inhibition by D-glucose when its present in 2-fold excess [58]. The closest homolog of Trire2_104072 among the characterized L-arabinose transporters, $P$. chrysogenum AraT, is inhibited by both $\mathrm{D}$-glucose and D-xylose although it can transport neither of these sugars [16]. The transporter with the most similar inhibition characteristics to Trire2_104072 is A. thaliana STP7, which is inhibited more severely by D-xylose than by D-glucose [25]. Majority of the other listed transporters were strongly inhibited by $\mathrm{D}$-glucose or $\mathrm{D}$-xylose, although the ratios of inhibitor and substrate varied strongly between the studies $[15,20$, 54]. 
Table 2 Inhibition characteristics of L-arabinose transporters from competition assays

\begin{tabular}{|c|c|c|c|c|c|}
\hline Organism & Transporter & Ratio & Glucose & Xylose & References \\
\hline A. thaliana & STP7 & 10 & 22 & 58 & [25] \\
\hline A. thaliana & STP2 ${ }^{\mathrm{a}}$ & 1 & n.c. & n.d. & [15] \\
\hline K. marxianus & Axt1 & 4 & 83 & 75 & [54] \\
\hline M. thermophila & LAT- $^{\text {b }}$ & 1 & $>95$ & n.d. & [20] \\
\hline N. crassa & LAT- $^{\text {b }}$ & 1 & $>95$ & n.d. & [20] \\
\hline $\begin{array}{l}\text { P. chrysoge- } \\
\text { num }\end{array}$ & AraT & 2 & 63 & 22 & [16] \\
\hline $\begin{array}{l}\text { P. guilliermon- } \\
\text { dii }\end{array}$ & Axt1 & 100 & 83 & 100 & [54] \\
\hline S. cerevisiae & Gal2 & 2 & 85 & 29 & [16] \\
\hline S. stipitis & $\operatorname{AraT}^{\mathrm{a}}$ & 1 & n.c. & n.d. & {$[15]$} \\
\hline T.reesei & 104072 & 5 & $0 \pm 8.2$ & $10.9 \pm 6.3$ & This study \\
\hline
\end{tabular}

Ratio is the concentration of the competing sugar divided by the concentration of $\mathrm{L}$-arabinose. Inhibition is shown as percentages

n.d. not determined

${ }^{a}$ n.c. $=$ reported as nearly complete inhibition

${ }^{b}$ Value estimated from graph

Based on its kinetic parameters and inhibition characteristics, Trire2_104072 could be a good candidate for metabolic engineering purposes. However, as shown by Bracher et al. [16] in experiments comparing PcAraT and ScGal2, the expression of a high-affinity, low-capacity transporter as the sole L-arabinose transporter might restrict the growth rate compared to the expression of a low-affinity, high-capacity transporter. On the other hand, processes relying solely on the low-affinity transporters suffer from the slowing down of fermentation when the sugar concentration decreases, and their low specificity causes the pentose sugars to be consumed only after D-glucose is consumed [78]. One solution would be to co-express both high-affinity and low-affinity transporters, but since many high-affinity transporters utilize the sugar/proton symport mechanism, concerns have been raised over the formation of a futile cycle [78]. This is because the symporters allow the accumulation of sugars against their concentration gradient at the expense of ATP, whereas the facilitators merely equilibrate the concentration gradient. Yet, it was observed that a strain expressing Gal2 and PcAraT performed better during anaerobic fermentation than a strain expressing Gal2 alone, and thus these concerns might have been only theoretical [58]. In some situations, the reduction of the ATP yield (e.g. by futile cycles or by the utilization of symporters instead of facilitators) might be beneficial because less ATP would be directed towards the formation of biomass [79]. One must also consider the energetic burden caused by the active transport mechanism itself, particularly in anaerobic conditions. A strain expressing PcAraT as the sole L-arabinose transporter failed to grow in anaerobic conditions, possibly due to not meeting the ATP production rate needed for cellular maintenance $[16,58]$. Expressing a symporter with higher transport rate could potentially solve this issue.

Besides potentially serving as a tool for improving L-arabinose fermentation of $S$. cerevisiae, the discovery of a highly specific L-arabinose transporter also sheds light into the L-arabinose metabolism of $T$. reesei. L-arabinose is present in the natural habitat of the fungus as part of cell wall polysaccharides, such as arabinoxylan, arabinogalactan and arabinan, of which the first is present in hemicellulose and the others in pectin $[1,80]$. The enzymes which are responsible for their degradation are expressed in response to $\mathrm{L}$-arabinose or its downstream metabolite L-arabitol, [66, 80]. The L-arabinose response is coregulated by XYR1 and ARA1 [36]. Deletion of both regulators is needed for removal of growth on L-arabinose or on D-xylose, while deletion of ARA1 alone abolishes growth on D-galactose [36]. The ARA1 ortholog of $N$. crassa (ARA-1) has been recently identified, and its deletion resulted in completely abolished growth on L-arabinose and D-galactose, while growth on D-xylose was not affected [38]. Downregulation of the L-arabinose transporter LAT-1 was observed in the $\Delta a r a-1$ mutant, and strain with lat-1 deletion was found to be unable to uptake L-arabinose and to have reduced growth on arabinan $[38,70]$. In $T$. reesei, deletion of the previously mentioned D-glucose/D-xylose transporter Trire2_50894 (STR1) was found to severely reduce growth on both D-xylose and L-arabinose and their sugar alcohol derivatives [29], which might indicate that it also has L-arabinose transport activity.

Concerning the importance of Trire2_104072 to T. ree$s e i$, it appears that it plays a more prominent role at low $\mathrm{L}$-arabinose concentrations as we noticed in our study. At higher concentrations its function can be likely compensated by some other transporter (e.g. STR1). It has been shown that $1 \mathrm{mM} \mathrm{L}$-arabinose is enough to result in induction of xylanase genes in T. reesei [66], which is below the limit where we observed the growth defect (3.33 $\mathrm{mM})$. These results indicate that the sugar transportome of $T$. reese $i$ is more fine-tuned than what has been previously thought.

It remains to be studied which transporters are responsible for conferring growth on D-xylose and L-arabinose in the $\Delta x y r 1$ and $\Delta a r a 1$ mutants. It could be hypothesized that STR1 is able to compensate for the loss of Trire2_104072 transport activity in the $\Delta$ ara 1 mutant, but likely not at low L-arabinose concentrations. Similarly, Trire2_104072 could compensate for the loss of STR1 transport activity in the $\Delta x y r 1$ mutant. However, the genome of $T$. reese $i$ possesses many uncharacterized 
transporters that might be able to transport D-xylose or L-arabinose.

\section{Conclusions}

In this study, the $T$. reesei $\mathrm{D}$-xylose transporter Trire2_104072 was shown to function as an $\mathrm{L}$-arabinose transporter. Analysis of a published transcriptome data set revealed that Trire2_104072 was highly expressed on medium containing $\mathrm{L}$-arabinose and that its expression was dependent on the presence of transcription factor ARA1, which regulates $\mathrm{L}$-arabinose and $\mathrm{D}$-galactose metabolism in T. reesei. Studies in two model systems, Xenopus and yeast, revealed that Trire_104072 transports L-arabinose with high affinity and D-xylose with low affinity. It also has a high affinity for protons, which ensures that it can operate in a relatively wide $\mathrm{pH}$ range. Its physiological role as a high-affinity transporter was suggested by the results from the deletion mutant, which had growth defect only at low concentrations of L-arabinose. At the time of its original discovery, Trire2_104072 was the first $\mathrm{D}$-xylose transporter discovered from $T$. reesei, and now it becomes the first specific L-arabinose transporter that has been characterized from this species. Remarkably, L-arabinose transport by Trire2_104072 was less inhibited by D-glucose and D-xylose than other known L-arabinose transporters. Therefore, this transporter could be valuable for metabolic engineering of yeast for optimal pentose utilization.

\section{Methods}

\section{Microbial media, cultivation and chemicals}

Yeast strains were cultured in rich YPD medium (1\% yeast extract, $2 \%$ peptone, $2 \% \mathrm{D}$-glucose) or in synthetic complete (SCD-Ura) medium $(0.67 \%$ yeast nitrogen base without amino acids, 2\% D-glucose, SC-Ura drop-out mix) [81]. Both media were supplemented with $2 \%$ agar for preparing solid media. Yeast was grown in $30{ }^{\circ} \mathrm{C}$ with $230 \mathrm{rpm}$ shaking in $50 \mathrm{~mL}$ volume in $250 \mathrm{~mL}$ flasks.

For growth and protein production studies, T. reesei was cultivated on minimal medium containing $15 \mathrm{~g} / \mathrm{L}$ $\mathrm{KH}_{2} \mathrm{PO}_{4}, 5 \mathrm{~g} / \mathrm{L}\left(\mathrm{NH}_{4}\right)_{2} \mathrm{SO}_{4}, 1 \mathrm{~mL} / \mathrm{L}$ trace element stock $\left(\mathrm{FeSO}_{4} \cdot 7 \mathrm{H}_{2} \mathrm{O} 5 \mathrm{~g} / \mathrm{L}, \mathrm{MnSO}_{4} \cdot \mathrm{H}_{2} \mathrm{O} 1.6 \mathrm{~g} / \mathrm{L}, \mathrm{ZnSO}_{4} \cdot 7 \mathrm{H}_{2} \mathrm{O}\right.$ $1.4 \mathrm{~g} / \mathrm{L}, \mathrm{CoCl}_{2} \cdot 6 \mathrm{H}_{2} \mathrm{O} 3.7 \mathrm{~g} / \mathrm{L}$ ) with indicated carbon source. SGE-lactose medium is minimal medium supplemented with $40 \mathrm{~g} / \mathrm{L}$ lactose, $20 \mathrm{~g} / \mathrm{L}$ spent grain extract, $100 \mathrm{mM}$ PIPPS and $8.6 \mathrm{~g} / \mathrm{L}$ di-ammonium citrate, and with ammonium sulfate replaced with $5.4 \mathrm{~g} / \mathrm{L} \mathrm{Na}_{2} \mathrm{SO}_{4}$. Both media were adjusted to $\mathrm{pH} 4.8$, and after autoclaving $\mathrm{MgSO}_{4}$ and $\mathrm{CaCl}_{2}$ were added to $2.4 \mathrm{mM}$ and 4.1 $\mathrm{mM}$ final concentrations, respectively. Solid media was supplemented with $20 \mathrm{~g} / \mathrm{L}$ agar and Triton X-100 (when appropriate) to restrict the spread of the mycelium. For the preparation of spore suspensions, T. reesei was grown on potato dextrose agar plates for $3-5$ days, and the spores were collected into a solution containing $0.8 \%$ $\mathrm{NaCl}, 0.025 \%$ Tween 20 and $20 \%$ glycerol and the resulting suspensions were stored in $-80{ }^{\circ} \mathrm{C}$.

24-well plate cultivations were used for the protein production and gene expression studies. Spores were inoculated to $2 \cdot 10^{5} \mathrm{cfu} / \mathrm{mL}$ concentration in $4 \mathrm{~mL}$ of medium per well, and the plates were incubated in $28{ }^{\circ} \mathrm{C}$ with 800 rpm shaking in Infors HT microtron incubator with 3 $\mathrm{mm}$ throw (Bottmingen, Switzerland). Growth profiling was done with Bioscreen $\mathrm{C}$ incubator (Oy Growth Curves Ab Ltd, Helsinki, Finland) with $200 \mu \mathrm{L}$ medium per well, and with the same spore concentration as in the 24-well plate studies. Incubation was done in $28{ }^{\circ} \mathrm{C}$ with continuous shaking (normal speed, maximal amplitude). Three and five replicate wells per strain were used in the 24-well plate cultivations and in the Bioscreen cultivations, respectively.

Chemicals were obtained from Merck KGaA (Darmstadt, Germany) and molecular biology reagents from Thermo Fisher Scientific (Waltham, MA, USA) unless otherwise mentioned. L-arabinose was obtained from Merck (Darmstadt, Germany), lactose was obtained from VWR (Helsinki, Finland), and L-rhamnose and L-sorbose were obtained from Fluka (Charlotte, NC, USA).

\section{Molecular biology methods}

High-fidelity PCR was done with KAPA HiFi polymerase (Roche, Basel, Switzerland) and colony PCR with DreamTaq polymerase (yeast, E. coli) or with Phire polymerase (T. reesei). Restriction digestions were performed with restriction enzymes from Thermo Fisher Scientific or NEB (Ipswich, MA, USA). E. coli transformations were done with electroporation, yeast transformations with the LiAc/ssDNA/PEG method described by Gietz and Woods [82] and T. reesei transformations as described by Penttilä et al. [83]. In vitro transcription was done with mMessage mMachine T7 kit. Primers were obtained from Thermo Fisher Scientific and they are listed in Additional file 1: Table S1.

\section{Plasmid and strain construction}

The genes coding for Trire2_104072 and Trire2_82309 were ordered as synthetic genes with codon-optimization for heterologous expression in yeast (GeneArt, Thermo Fisher Scientific). For Trire2_104072 we used the version from the RUT-C30 genome assembly (TrireRUTC30_33630; GenBank ETS04871.1). For Trire2_82309 (TrireRUT-C30_26932, GenBank ETR97140) the versions in the QM6a and RUT-C30 genome assemblies are identical. The yeast expression plasmids for Trire2_104072 and Trire2_82309 were constructed with the Yeast MoClo toolkit [84]. The plasmids harboring the 
genes in a pMA-T backbone, as well as MoClo plasmids pYTK-2, -11, -51, -67, -74, -82 and -84 were digested with $B s a \mathrm{I}-\mathrm{HF}^{\circledR} \mathrm{v} 2$ and ligated with T4 ligase (both from NEB). The reaction was performed simultaneously in a thermocycler as described by Lee et al. [84]. The resulting plasmids, B11037 and B11554 (Table 3), were sequenced with primers SaSS-19 and -20.

Genes coding for P. chrysogenum AraT (Pc20g01790, GenBank CAP85508.1), P. guilliermondii Axt1 (GenBank GZ791040.1) and N. crassa LAT-1 (NCU02188, GenBank XP_959582.3) were ordered as synthetic genes with codon optimization for yeast expression (Twist Biosciences, San Francisco, CA, USA). The genes were ligated to pFL60 via Gibson assembly (NEB) and the resulting plasmids (B11394, B11395 and B11396) were verified by sequencing with primers SaSS-98 and -99 .

Plasmids B1687, B2013 (pFL60), B2251, B2253 and B10862 were from our institution's strain collection. pFL60 contains PGK1 promoter and terminator, URA3 gene for selection in yeast and the $2 \mu \mathrm{m}$ replication origin [85]. B1687 contains the $x l t 1$ gene in pAJ401 backbone which similarly to pFL60 harbors PGK1 promoter, $U R A 3$ and $2 \mu \mathrm{m}$ origin [14]. B2251 contains the A. monospora LAT1 gene in modified pFL60 vector [18]. B10862 contains the $A$. thaliana STP7 gene in pFL60 and was constructed by Dr. Peter Richard of VTT from a plasmid containing STP7 cDNA which was provided by Dr. Ruth Stadler (University Erlangen-Nürnberg, Erlang, Germany). B2253 contains the GAL2 gene under the control of $A D H 1$ promoter in pVT100-U vector [86]. Yeast expression plasmids were transformed into yeast strain H2805 (CEN.PK2-1D: MAT $\alpha$ ura3-52 his3- $\Delta 1$ leu2-3,112 trp1-289 MAL2-8 SUC2) and transformants were selected on synthetic complete medium which lacked uracil.

For expression in $X$. laevis oocytes, the oocyte expression vector Pol1 was modified to be compatible with the yeast MoClo system. To modify the MCS, the Pol1 plasmid was digested with EcoRI and BamHI before ligation of the fragment containing the $B s a \mathrm{I}$ sites, which was digested with the same enzymes. The fragment was constructed by annealing oligos SaSS-43 and -44 . The MoClo-compatible version of Pol1, which was named B10213, was digested with $B s a \mathrm{I}$ and the two resulting fragments (Pol1 contains one endogenous BsaI site) were gel purified. The backbone fragments were ligated with the Trire2_104072 insert, which was liberated from the pMA-T backbone with BsaI. The resulting plasmid B10219 was sequenced with T7 promoter primer and SaSS-57 primer.

Deletion vector for Trire2_104072 was constructed by amplifying the $5^{\prime}$ and $3^{\prime}$ flanking regions from $T$. reesei genomic DNA with primers SaSS-101, -104, -155 and -156. The genomic DNA was prepared with the Easy DNA kit (ThermoFisher Scientific) according to kit instructions. The deletion vector was constructed with yeast homologous recombination using yeast strain FY834 [87, 88]. To do this, the amplicons were

Table 3 Plasmids used in this study

\begin{tabular}{|c|c|c|}
\hline Name & Description & References \\
\hline \multicolumn{3}{|c|}{ Electrophysiology } \\
\hline Pol1 & Oocyte expression vector & [107] \\
\hline B10213 & Pol1 with modified multiple cloning site & This study \\
\hline B10219 & B10213 with Trire2_104072 & This study \\
\hline \multicolumn{3}{|c|}{ Yeast studies } \\
\hline B1687 & xlt1 (Trire2_104072 $\left.2^{\mathrm{P} 388 \mathrm{H}}\right)$ in pAJ401 ( $\left.\mathrm{P}_{P G K 1}, U R A 3,2 \mu \mathrm{m}\right)$ & {$[14]$} \\
\hline B2013 & Yeast expression vector pFL60 (P $\left.P_{P G K 1}, U R A 3,2 \mu \mathrm{m}\right)$ & {$[85]$} \\
\hline B2251 & A. monospora LAT1 in modified pFL60 & {$[18]$} \\
\hline B2253 & GAL2 in pVT100-U (P $\left.P_{A D H 1}, U R A 3,2 \mu \mathrm{m}\right)$ & {$[86]$} \\
\hline B10862 & A. thaliana STP7 in pFL60 & $\begin{array}{l}\text { Peter Richard, } \\
\text { unpublished }\end{array}$ \\
\hline B1 1037 & Trire2_104072 in MoClo-based expression vector $\left(P_{P G K 1}, U R A 3,2 \mu \mathrm{m}\right)$ & This study \\
\hline B11394 & P. chrysogenum araT in pFL60 & This study \\
\hline B11395 & N. crassa lat-1 in pFL60 & This study \\
\hline B11396 & P. guilliermondii AXT1 in pFL60 & This study \\
\hline B11554 & Trire2_82309 in MoClo-based expression vector $\left(P_{P G K 1}, U R A 3,2 \mu \mathrm{m}\right)$ & This study \\
\hline \multicolumn{3}{|c|}{ T. reeseistudies } \\
\hline B11697 & Trire2_104072 deletion vector (pyr4) & This study \\
\hline
\end{tabular}


transformed to yeast along with pRS426 backbone [89], which was digested with EcoRI and $X b a \mathrm{I}$ and gel purified, and with pyr4 fragment which was prepared as described by Landowski et al. [69]. The resulting transformants were pooled and the plasmids were rescued with glass bead extraction followed by plasmid miniprep and transformed into E. coli. Plasmids were extracted from the transformant colonies and verified by digestion and with sequencing with primers T27, T60, T552 and T553. Plasmid harboring the correct sequence (B11697) was transformed into T. reesei production strain M44 [69]. The transformant colonies were screened with primers T27, T60, SaSS-166, SaSS-167, SaSS-168 and SaSS-169 to verify correct integration to the Trire2_104072 locus. The correct colonies were purified into homokaryons and screened again with PCR. Spore suspensions created from two different transformants were used for the studies, along with two separate spore suspensions made from M44 which served as biological replicates.

\section{Preparation of mRNA and $X$. laevis oocyte injection}

The pol1-based plasmid containing the Trire2_104072 CDS was linearized with NheI and in vitro transcribed into mRNA. After the transcription the product was purified with $\mathrm{LiCl}$ precipitation according to the kit instructions.

Oocytes were obtained via surgery as described by Clemencon et al. [90]. Briefly, adult female $X$. laevis frogs were anaesthetized with 3 -aminobenzoate methanesulfonate $(1 \mathrm{~g} / \mathrm{L}$ in ice-water slurry) and the oocytes were removed with surgery. Oocytes were suspended in modified Barth's medium with $\mathrm{Ca}^{2+}\left(\mathrm{MBM}+\mathrm{Ca}^{2+} ; 88 \mathrm{mM}\right.$

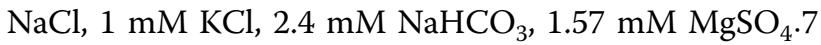
$\mathrm{H}_{2} \mathrm{O}, 0.66 \mathrm{mM} \mathrm{NaNO}_{3}, 0.75 \mathrm{mM} \mathrm{CaCl}, 10 \mathrm{mM}$ HEPES), which was supplemented with penicillin and streptomycin, and the oocyte sacs were separated to 3-4 mm pieces with forceps.

The oocytes were defolliculated by collagenase treatment. The oocytes were washed with $\mathrm{MBM}-\mathrm{Ca}^{2+}$ $\left(\mathrm{MBM}+\mathrm{Ca}^{2+}\right.$ without $\left.\mathrm{CaCl}_{2}\right)$, after which they were suspended to the same buffer containing $4 \mathrm{~g} / \mathrm{L}$ collagenase (NB4, SERVA Electrophoresis GmbH, Heidelberg, Germany) and incubated in rocking shaker for $1 \mathrm{~h}$. After the incubation, the washing and collagenase treatment steps were repeated. Finally the oocytes were washed with $\mathrm{MBM}+\mathrm{Ca}^{2+}$ and healthy stage V-VI oocytes were picked.

The oocytes were injected with 30 ng Trire2_104072 mRNA in $50 \mathrm{~nL}$ volume or with the same volume of water. The injection was done with Nanoject II microinjector (Drummond Scientific, Broomall, PA, USA). After injection the oocytes were suspended in $\mathrm{MBM}+\mathrm{Ca}^{2+}$ and incubated in $17^{\circ} \mathrm{C}$ for $3-7$ days.

\section{Electrophysiology experiments with $X$. laevis oocytes}

Two-electrode voltage clamp (TEVC) technique was used for the electrophysiological characterization. In this method, the membrane potential of the oocyte is clamped to a specific voltage and the transport is measured by recording the substrate-induced changes in the membrane current [41]. The measurements were done on a TEVC setup consisting of 2-channel perfusion system, OC-725C Oocyte clamp amplifier (Warner Instruments, Hamden, CT, USA) and Axon Digidata 1440A digitizer (Molecular Devices, San Jose, CA, USA). The system was calibrated with oocyte model cell. Microelectrodes filled with $3 \mathrm{M} \mathrm{KCl}$ and with resistance between 0.5-5 M $\Omega$ were used. pClamp software suite (Molecular Devices) was used for the analysis. ND-96 buffer without sodium $\left(100 \mathrm{mM}\right.$ choline, $2 \mathrm{mM} \mathrm{KCl}, 1 \mathrm{mM} \mathrm{CaCl}_{2}$. $2 \mathrm{H}_{2} \mathrm{O}, 1 \mathrm{mM} \mathrm{MgCl} \cdot 6 \mathrm{H}_{2} \mathrm{O}, 3 \mathrm{mM}$ HEPES) was used for the experiments. Each experiment was done with at least three oocytes derived from at least two different frogs, except for the pre-steady state kinetics which were done with two oocytes derived from two different frogs.

For the current trace recordings, the oocytes were perfused with ND-96 (pH 7.4) and clamped at $-50 \mathrm{mV}$. For each sugar, the oocyte was first perfused with ND-96 $(\mathrm{pH}$ 7.4) until the current stabilized, then with ND-96 $(\mathrm{pH}$ 5.5) until the current stabilized and finally with ND-96 (pH 5.5) containing $5 \mathrm{mM}$ sugar. Afterwards the current was recovered to baseline by perfusing with ND-96 ( $\mathrm{pH}$ 7.4). The resulting current traces were recorded with Axoscope program of the pClamp software suite.

The I-V curves were recorded with Clampex program of the pClamp software suite. The oocytes were clamped at $-50 \mathrm{mV}$, perfused with the test solution until the current stabilized and then $200 \mathrm{~ms}$ step-wise changes of membrane potential from -150 to $50 \mathrm{mV}$ were applied. For each measurement, a recording was done first with buffer alone and then with the same buffer which contained the sugar to be analyzed. The steady-state currents obtained in the absence of sugar were subtracted from the currents obtained in the presence of sugar for each of the tested voltages. Between measurements the oocyte was stabilized by perfusing with $\mathrm{pH} 7.4$ buffer.

The selectivity was measured by recording I-V curves with $5 \mathrm{mM}$ sugar solutions in $\mathrm{pH}$ 5.5. For the kinetics experiments $\mathrm{I}-\mathrm{V}$ curve recordings were done with different sugar concentrations with $\mathrm{pH} 5.5$ buffer. For the $\mathrm{pH}$-dependence experiments, I-V curve recordings were done with ND-96 (with $5 \mathrm{mM}$ L-arabinose) adjusted to different $\mathrm{pH}$ values. Normalized currents were calculated by dividing the obtained currents with the highest negative current obtained at $-50 \mathrm{mV}$ during the experiment. The kinetics parameters for L-arabinose and D-xylose were calculated by fitting the normalized currents as a 
function of substrate concentration to Michaelis-Menten (Eq. 1), where $I_{\max }=$ maximum current, $[S]=$ substrate concentration and $K_{m}=$ Michaelis constant. For the calculation of the turnover number (see below), unnormalized currents were used for the fitting to obtain the $I_{\max }$. The fitting was done with the $\mathrm{nl}$ s package for $\mathrm{R}$ with the default Gauss-Newton algorithm. The $K_{\mathrm{m}}$ and $I_{\max }$ values are presented as mean \pm standard deviation from three different oocytes.

$$
I=\frac{I_{\max }[S]}{[S]+K_{m}}
$$

The kinetics parameters for $\mathrm{pH}$-dependency were calculated similarly, but the data was fitted to Hill equation (Eq. 2), where $n$ is the Hill coefficient and $K_{0.5}$ is the proton concentration where $I$ reaches half of the maximum current $I_{\max }$.

$$
I=\frac{I_{\max }[S]^{n}}{[S]^{n}+K_{0.5}^{n}}
$$

Pre-steady state kinetics were analyzed from I-V curves which were obtained in ND-96 buffer with different $\mathrm{pH}$ values but without sugar. The pre-steady state currents were isolated as previously described [63]. The presteady state currents were integrated with respect to time to obtain the charge transfer $(\mathrm{Q})$ which were fitted to the following Boltzmann relation (Eq. 3), where $Q=$ total charge, $Q_{h y p}=$ charge transfer at hyperpolarizing limit, $Q_{d e p}=$ charge transfer at depolarizing limit, $Q_{\max }$ $=Q_{d e p}-Q_{h y p}, z=$ apparent valence, $V=$ voltage, $V_{0.5}=$ voltage at the midpoint of charge transfer, $F=$ Faraday's constant, $R=$ Gas constant and $T=$ temperature. The transporter turnover number is defined as $I_{\max } / Q_{\max }$ [63], where $I_{\max }$ is the maximum current obtained from the Michaelis-Menten fit for the kinetics measurements and $Q_{\max }$ value is obtained from I-V curve measurement at $\mathrm{pH} 5.5$ without sugar.

$$
\frac{Q-Q_{h y p}}{Q_{\max }}=\frac{1}{1+\exp \left[\frac{\mathrm{zF}\left(\mathrm{V}-\mathrm{V}_{0.5}\right)}{\mathrm{RT}}\right]}
$$

\section{Sugar uptake assays}

Radioactive ${ }^{14} \mathrm{C}-1$-L-arabinose (MC 2019, lot 165-155-054-A-20020115-SB) from Moravek Biochemicals (Brea, CA, USA) was used for transport experiments. Zero-trans uptake assays were performed as previously described [33]. Briefly, yeast cells were harvested in the exponential phase, washed with ice-cold water and resuspended in ice-cold assay buffer to yield a cell suspension with 40-60 OD/mL. Assay buffer was $100 \mathrm{mM}$ potassium phosphate buffer ( $\mathrm{pH} 6.5$ in $20{ }^{\circ} \mathrm{C}$ ), except in the experiment with lower $\mathrm{pH}$ where $100 \mathrm{mM}$ sodium citrate buffer ( $\mathrm{pH} 4.5$ at $\left.20^{\circ} \mathrm{C}\right)$ was used. Aliquots of the cell suspension and sugar solutions were kept for 5 minutes in $28{ }^{\circ} \mathrm{C}$ water bath before mixing $40 \mu \mathrm{L}$ cells with $20 \mu \mathrm{L} 3 \mathrm{x}$ sugar solution in a glass tube with conical bottom. After incubation of desired length, the reaction was quenched with $10 \mathrm{~mL}$ of ice-cold water. The mixture was filtrated with prewetted Whatman GF/C filter paper (GE Healthcare, Helsinki, Finland) and the tube was washed with another $10 \mathrm{~mL}$ ice-cold water. The filter paper was transferred into scintillation vial containing $4 \mathrm{~mL}$ Ultima Gold XR liquid scintillation cocktail (PerkinElmer, Waltham, MA, USA) and counted with TriCarb 2810 TR scintillation counter (PerkinElmer). Blanks were performed to measure unspecific binding of the sugar to cell surface: $20 \mu \mathrm{L} 3 \mathrm{x}$ sugar solution and $40 \mu \mathrm{L}$ cells were pipetted into $10 \mathrm{~mL}$ ice-cold water, which was treated afterwards in similar way as normal samples. To ensure that the uptake was in the linear range, the uptake rate obtained from two different timepoints was compared.

Uptake rate was calculated by dividing the blank-subtracted counts by reaction time (min), amount of yeast (OD) used and specific activity of the radioactive stock solution $(\mathrm{cpm} / \mathrm{nmol})$. The relationship between OD and $\mathrm{CDW}$ was measured to be $0.252 \mathrm{mg}_{\mathrm{CDW}} \mathrm{OD}^{-1}$. Two to three technical replicates were used for each sample. Specific uptake rate was defined as uptake rate subtracted with uptake rate obtained for the control strain with the empty plasmid. Kinetics results were fitted to MichaelisMenten equation with nonlinear least squares estimation with the R package nls.

\section{RNA extraction and RT-qPCR}

RNeasy plant mini kit (Qiagen, Hilden, Germany) was used for the extraction of fungal total RNA. Cultures of three replicate wells were pooled and subjected to RNA extraction which was done as previously described [33]. Afterwards, $1 \mu \mathrm{g}$ RNA was treated with DNAse I and reverse-transcribed with Transcriptor First Strand cDNA synthesis kit (Roche) with anchored oligo-dT primers. qPCR was done with Sybr Green I mix (Roche) with Trire2_104072 and bgal as the target genes and Sar1 and $g p d 1$ as the reference genes. The use of $s a r 1$ for this purpose has been suggested previously [91]. Primers are listed in Additional file 1: Table S1.

The results were analyzed with the $\Delta \Delta \mathrm{C}_{\mathrm{p}}$ method by Livak and Schmittgen [92]. Fold-changes were calculated according to Eq. 4, where $\Delta C_{p}$ is the difference between $C_{p}$ values obtained for the target gene and the reference genes $\left(C_{p, \text { target }}-C_{p \text {,control }}\right)$. Arithmetic mean of the $C_{p}$ values obtained for the reference genes was used. The term $2^{-\Delta C_{p}}$ was defined as the expression level. The obtained fold-changes were further $\log _{2}$-transformed. 


$$
\frac{2^{-\Delta C_{p, a r a}}}{2^{-\Delta C_{p, g l c}}}
$$

\section{Expression data analysis}

Expression data was derived from Gene Expression omnibus (GEO) database (Accession number GSE104606) [93], and it is related to results published by Benocci et al. [36]. In the article, T. reesei QM9414 and its $\Delta x y r 1, \Delta$ ara 1 and $\Delta x y r 1 \Delta a r a 1$ mutants were inoculated as spores to complex medium with $2 \%$ D-fructose as the carbon source. After $20 \mathrm{~h}$ of growth $\left(28{ }^{\circ} \mathrm{C}, 250\right.$ $\mathrm{rpm})$, mycelia were washed and transferred to minimal medium with $25 \mathrm{mM} \mathrm{L}$-arabinose or $25 \mathrm{mM}$ D-galactose as the carbon source. RNA was extracted from mycelium samples for RNA-sequencing $2 \mathrm{~h}$ after incubation in minimal medium. RNA-sequencing was performed with Illumina technology [36].

T. reesei sugar transporters which have been published were chosen for the analysis. Few putative sugar transporters that have shown interesting properties in previous studies were also included. The published sugar transporters are putative D-glucose transporter Trire2_22912 (HXT1) [45], D-xylose facilitator Trire2_63966 (XLTR1) [32], D-glucose/D-xylose transporters Trire2_50894 (STR1) [26, 29], Trire2_121482 (STR2) [26] and Trire2_62380 (STR3) [26], D-glucose/cellobiose facilitator Trire2_47710 (STP1) [30, 42], D-galacturonic acid transporters Trire2_69026 and Trire2_106330 [11], putative lactose transporters Trire2_79202 and Trire2_77517 [94], cellobiose transporter Trire2_67752 [31], D-xylose/cellobiose/Dmannose transporter Trire2_69957 [44] and cellobiose/ lactose transporter Trire2_3405 (CRT1) [30, 33, 43]. The putative sugar transporters were Trire2_106556 which is the homolog of $N$. crassa low-affinity D-glucose transporter GLT-1 [73], Trire2_82309 which has been shown to be upregulated in cellulase-inducing conditions [95], Trire2_56684 which has been shown to be part of lightregulated genome cluster which also contains cellulases cbh 2 and egl2 and whose promoter has been shown to bind XYR1 [37, 47], and Trire2_46819 which is the closest homolog (72\% identity with BLASTp) of the $N$. crassa cellobionic acid transporter CLP-1/CBT-1 in T. reesei [96, 97]. Trire2_56684 and Trire2_46819 were also reported to be regulated by transcription factor AZF1 in a recent report [98]. However, Trire2_63966 was omitted from the figures due to its low expression level in all conditions.

\section{Phylogenetic analysis}

The amino acid sequences of the transporters were obtained from GenBank (accession numbers are listed in Additional file 1: Table S2). Sequence alignment was done with MUSCLE [99] and the phylogenetic analysis was performed with maximum likelihood method with 100 bootstrap runs [100]. Both steps were performed with MEGA X software [101]. The tree was visualized with ape package for $\mathrm{R}$ [102]. Visualization of the alignment was done with msa package for $\mathrm{R}$ using MUSCLE method [103].

\section{Supplementary Information}

The online version contains supplementary material available at https://doi. org/10.1186/s12934-021-01666-4.

Additional file 1: Table S1. List of primers used in this study. Table S2. Accession numbers for sequences used in the phylogenetic analysis.

Figure S1. Gene expression analysis of selected T. reesei transporters on L-arabinose and D-galactose. Figure S2. Subset of the multiple alignment of transporter amino acid sequences. Figure S3. Analysis of voltagedependence of Trire2_104072 kinetics. Figure S4. Analysis of pre-steady state kinetics of Trire2_104072. Figure S5. Characterization of the $\Delta$ Trire2_104072 mutant.

\section{Acknowledgements}

Prof. Doris Rentsch of University of Bern is acknowledged for the use of her frog facility. PD Dr. Ruth Stadler is acknowledged for providing the STP7 CDNA. Dr. Peter Richard is acknowledged for constructing and providing the B10862 plasmid. Prof. Matthias Hediger furthermore acknowledges the support of the electrophysiological functional studies of the transporters by the Swiss National Science Foundation Grant Sinergia \#CRSII5 180326.

\section{Authors' contributions}

$\mathrm{SH}$ designed some of the constructs, did the cloning, performed the analysis and drafted the manuscript. JPG performed the surgery to obtain the oocytes, participated in the electrophysiology studies, and helped in drafting the manuscript. MV designed the constructs for expressing Trire2_104072 and Trire2_82309, read and commented on the manuscript. MH planned the collaboration, read and commented on the manuscript. CLP edited the manuscript, planned the collaboration and designed some of the studies. All authors read and approved the final manuscript.

\section{Funding}

The work was funded by Academy of Finland (funding decision No. 298392). Prof. Matthias Hediger acknowledges the support of the electrophysiology studies by the Swiss National Science Foundation Grant Sinergia \#CRSII5 180326 .

Availability of data and materials

The datasets generated during the current study are available from the corresponding author on reasonable request.

\section{Declarations}

\section{Ethics approval and consent to participate}

All experiments using the $X$. laevis animals were in accordance with the Swiss Animal Welfare law and approved by the local Veterinary Authority (Amt für Veterinärwesen Kantons Bern; Permit Number: BE60/2018).

\section{Consent for publication}

Not applicable.

\section{Competing interests}

The authors declare that they have no competing interests.

\section{Author details}

${ }^{1} \mathrm{VTT}$ Technical Research Center of Finland Ltd, Tietotie 2, 02150 Espoo,

Finland. ${ }^{2}$ Membrane Transport Discovery Lab, Department of Nephrology 
and Hypertension, University of Bern, Freiburgstrasse 15, 3010 Bern, Switzerland. ${ }^{3}$ Department of Biomedical Research, Inselspital, University of Bern, Freiburgstrasse 15, 3010 Bern, Switzerland.

Received: 8 February 2021 Accepted: 25 August 2021 Published online: 08 September 2021

\section{References}

1. Mäkelä MR, Donofrio N, de Vries RP. Plant biomass degradation by fungi. Fungal Gen Biol. 2014;72:2-9.

2. Nielsen J, Larsson C, van Maris A, Pronk J. Metabolic engineering of yeast for production of fuels and chemicals. Curr Opin Biotechnol. 2013;24(3):398-404.

3. Van Zyl WH, Lynd LR, den Haan R, McBride JE. Consolidated bioprocessing for bioethanol production using Saccharomyces cerevisiae. In: Olsson L, editor. Biofuels of advances in biochemical engineering/biotechnology, vol. 108. Berlin: Springer; 2007. p. 205-35.

4. Rytioja J, Hildén K, Yuzon J, Hatakka A, de Vries RP, Mäkelä MR. Plantpolysaccharide-degrading enzymes from basidiomycetes. Microbiol Mol Biol Rev. 2014;78(4):614-49.

5. Rabemanolontsoa H, Saka S. Comparative study on chemical composition of various biomass species. RSC Adv. 2013;3(12):3946-56.

6. Hahn-Hägerdal B, Karhumaa K, Fonseca C, Spencer-Martins I, GorwaGrauslund MF. Towards industrial pentose-fermenting yeast strains. Appl Microbiol Biotechnol. 2007;74(5):937-53.

7. Moysés DN, Reis VCB, Almeida JRMD, Moraes LMPD, Torres FAG. Xylose fermentation by Saccharomyces cerevisiae: challenges and prospects. Int J Mol Sci. 2016;17(3):207.

8. Ye S, Jw Kim, Kim SR. Metabolic engineering for improved fermentation of L-arabinose. J Microbiol Biotechnol. 2019;29:339-46.

9. Nijland JG, Driessen AJ. Engineering of pentose transport in Saccharomyces cerevisiae for biotechnological applications. Front Bioeng Biotechnol. 2020;7:464.

10. Müller-Maatsch J, Bencivenni M, Caligiani A, Tedeschi T, Bruggeman $\mathrm{G}$, Bosch $\mathrm{M}$, et al. Pectin content and composition from different food waste streams. Food Chem. 2016;201:37-45.

11. Protzko RJ, Latimer LN, Martinho Z, de Reus E, Seibert T, Benz JP, et al. Engineering Saccharomyces cerevisiae for co-utilization of D-galacturonic acid and D-glucose from citrus peel waste. Nat Commun. 2018;9(1):1-10.

12. Jeong D, Park H, Jang BK, Ju Y, Shin MH, Oh EJ, et al. Recent advances in the biological valorization of citrus peel waste into fuels and chemicals. Bioresour Technol. 2021;323:124603.

13. Kuivanen J, Biz A, Richard P. Microbial hexuronate catabolism in biotechnology. AMB Expr. 2019;9(1):1-11.

14. Saloheimo A, Rauta J, Stasyk V, Sibirny AA, Penttilä M, Ruohonen L. Xylose transport studies with xylose-utilizing Saccharomyces cerevisiae strains expressing heterologous and homologous permeases. Appl Microbiol Biotechnol. 2007;74(5):1041-52.

15. Subtil T, Boles E. Improving L-arabinose utilization of pentose fermenting Saccharomyces cerevisiae cells by heterologous expression of L-arabinose transporting sugar transporters. Biotechnol Biofuels. 2011;4(38):1-10.

16. Bracher JM, Verhoeven MD, Wisselink HW, Crimi B, Nijland JG, Driessen AJ, et al. The Penicillium chrysogenum transporter PcAraT enables highaffinity, glucose-insensitive L-arabinose transport in Saccharomyces cerevisiae. Biotechnol Biofuels. 2018;11(1):63.

17. Knoshaug EP, Franden MA, Stambuk BU, Zhang M, Singh A. Utilization and transport of L-arabinose by non-Saccharomyces yeasts. Cellulose. 2009;16(4):729-41.

18. Verho R, Penttilä M, Richard P. Cloning of two genes (LAT1, 2) encoding specific $L$-arabinose transporters of the L-arabinose fermenting yeast Ambrosiozyma monospora. Appl Biochem Biotechnol. 2011;164(5):604-11.

19. Li J, Lin L, Li H, Tian C, Ma Y. Transcriptional comparison of the filamentous fungus Neurospora crassa growing on three major monosaccharides D-glucose, D-xylose and L-arabinose. Biotechnol Biofuels. 2014;7(1):31.
20. Li J, Xu J, Cai P, Wang B, Ma Y, Benz JP, et al. Functional analysis of two L-arabinose transporters from filamentous fungi reveals promising characteristics for improved pentose utilization in Saccharomyces cerevisiae. Appl Environ Microbiol. 2015;81(12):4062-70.

21. Desai TA, Rao CV. Regulation of arabinose and xylose metabolism in Escherichia coli. Appl Environ Microbiol. 2010;76(5):1524-32.

22. Kawaguchi H, Sasaki M, Vertès AA, Inui M, Yukawa H. Identification and functional analysis of the gene cluster for L-arabinose utilization in Corynebacterium glutamicum. Appl Environ Microbiol. 2009;75(11):3419-29.

23. Krispin O, Allmansberger R. The Bacillus subtilis AraE protein displays a broad substrate specificity for several different sugars. J Bacteriol. 1998;180(12):3250-2.

24. Shatwell KP, Charalambous BM, McDonald TP, Henderson P. Cloning, sequencing, and expression of the araE gene of Klebsiella oxytoca 8017, which encodes arabinose- $\mathrm{H}^{+}$symport activity. J Bacteriol. 1995;177(18):5379-80.

25. Rottmann T, Klebl F, Schneider S, Kischka D, Rüscher D, Sauer N, et al. Sugar transporter STP7 specificity for L-arabinose and D-xylose contrasts with the typical hexose transporters STP8 and STP12. Plant Physiol. 2018;176(3):2330-50.

26. Sloothaak J, Tamayo-Ramos JA, Odoni DI, Laothanachareon T, Derntl C, Mach-Aigner AR, et al. Identification and functional characterization of novel xylose transporters from the cell factories Aspergillus niger and Trichoderma reesei. Biotechnol Biofuels. 2016;9(1):148.

27. Nogueira KMV, Mendes V, Carraro CB, Taveira IC, Oshiquiri LH, Gupta VK, et al. Sugar transporters from industrial fungi: Key to improving second-generation ethanol production. Renew Sustain Energy Rev. 2020;131:109991.

28. Chaudhary N, Kumari I, Sandhu P, Ahmed M, Akhter Y. Proteome scale census of major facilitator superfamily transporters in Trichoderma reese using protein sequence and structure based classification enhanced ranking. Gene. 2016;585(1):166-76.

29. Huang ZB, Chen XZ, Qin LN, Wu HQ, Su XY, Dong ZY. A novel major facilitator transporter TrSTR1 is essential for pentose utilization and involved in xylanase induction in Trichoderma reesei. Biochem Biophys Res Commun. 2015;460(3):663-9.

30. Zhang W, Kou Y, Xu J, Cao Y, Zhao G, Shao J, et al. Two major facilitator superfamily sugar transporters from Trichoderma reesei and their roles in induction of cellulase biosynthesis. J Biol Chem. 2013;288:32861-72.

31. Casa-Villegas M, Polaina J, Marín-Navarro J. Cellobiose fermentation by Saccharomyces cerevisiae: comparative analysis of intra versus extracellular sugar hydrolysis. Process Biochem. 2018;75:59-67.

32. Jiang Y, Shen Y, Gu L, Wang Z, Su N, Niu K, et al. Identification and characterization of an efficient D-xylose transporter in Saccharomyces cerevisiae. J Agric Food Chem. 2020;68(9):2702-10.

33. Havukainen S, Valkonen M, Koivuranta K, Landowski CP. Studies on sugar transporter CRT1 reveal new characteristics that are critical for cellulase induction in Trichoderma reesei. Biotechnol Biofuels. 2020;13(1):1-20.

34. dos Santos Castro L, de Paula RG, Antoniêto AC, Persinoti GF, SilvaRocha R, Silva RN. Understanding the role of the master regulator XYR1 in Trichoderma reesei by global transcriptional analysis. Front Microbiol. 2016;7:175.

35. Häkkinen M, Valkonen MJ, Westerholm-Parvinen A, Aro N, Arvas M, Vitikainen $M$, et al. Screening of candidate regulators for cellulase and hemicellulase production in Trichoderma reesei and identification of a factor essential for cellulase production. Biotechnol Biofuels. 2014;7(1):14.

36. Benocci T, Aguilar-Pontes MV, Kun RS, Seiboth B, de Vries RP, Daly P. ARA1 regulates not only L-arabinose but also D-galactose catabolism in Trichoderma reesei. FEBS Lett. 2018;592(1):60-70.

37. Ma L, Chen L, Zhang L, Zou G, Liu R, Jiang Y, et al. RNA sequencing reveals Xyr1 as a transcription factor regulating gene expression beyond carbohydrate metabolism. BioMed Res Int. 2016. https://doi. org/10.1155/2016/4841756.

38. Wu VW, Thieme N, Huberman LB, Dietschmann A, Kowbel DJ, Lee J, et al. The regulatory and transcriptional landscape associated with carbon utilization in a filamentous fungus. Proc Natl Acad Sci USA. 2020;117(11):6003-13. 
39. De Souza WR, Maitan-Alfenas GP, de Gouvêa PF, Brown NA, Savoldi M, Battaglia $\mathrm{E}$, et al. The influence of Aspergillus niger transcription factors AraR and $X \ln R$ in the gene expression during growth in $D$-xylose, L-arabinose and steam-exploded sugarcane bagasse. Fungal Genet Biol. 2013:60:29-45.

40. Wang C, Bao X, Li Y, Jiao C, Hou J, Zhang Q, et al. Cloning and characterization of heterologous transporters in Saccharomyces cerevisiae and identification of important amino acids for xylose utilization. Metab Eng. 2015;30:79-88.

41. Guan B, Chen X, Zhang H. Two-electrode voltage clamp. In: Gamper N, editor. Ion channels: methods and protocols of Methods in molecular biology, vol. 998. New York: Springer; 2013. p. 79-89.

42. Zhang W, Cao Y, Gong J, Bao X, Chen G, Liu W. Identification of residues important for substrate uptake in a glucose transporter from the filamentous fungus Trichoderma reesei. Sci Rep. 2015;5(1):1-10.

43. Ivanova C, Bååth JA, Seiboth B, Kubicek CP. Systems analysis of lactose metabolism in Trichoderma reesei identifies a lactose permease that is essential for cellulase induction. PLoS ONE. 2013;8(5):e62631.

44. Nogueira KM, de Paula RG, Antoniêto ACC, dos Reis TF, Carraro CB, Silva $A C$, et al. Characterization of a novel sugar transporter involved in sugarcane bagasse degradation in Trichoderma reesei. Biotechnol Biofuels. 2018:11(1):84.

45. Ramos AS, Chambergo FS, Bonaccorsi ED, Ferreira AJ, Cella N, Gombert AK, et al. Oxygen-and glucose-dependent expression of Trhxt1, a putative glucose transporter gene of Trichoderma reesei. Biochemistry. 2006;45(26):8184-92.

46. Martinez D, Berka RM, Henrissat B, Saloheimo M, Arvas M, Baker SE, et al. Genome sequencing and analysis of the biomass-degrading fungus Trichoderma reesei (syn. Hypocrea jecorina). Nat Biotechnol. 2008;26(5):553-60.

47. Stappler E, Dattenböck C, Tisch D, Schmoll M. Analysis of light-and carbon-specific transcriptomes implicates a class of G-protein-coupled receptors in cellulose sensing. Msphere. 2017;2(3):e00089-17.

48. Jourdier E, Baudry L, Poggi-Parodi D, Vicq Y, Koszul R, Margeot A, et al. Proximity ligation scaffolding and comparison of two Trichoderma reesei strains genomes. Biotechnol Biofuels. 2017;10(1):1-13.

49. Krogh A, Larsson B, Von Heijne G, Sonnhammer EL. Predicting transmembrane protein topology with a hidden Markov model: application to complete genomes. J Mol Biol. 2001;305(3):567-80.

50. Dobson L, Reményi I, Tusnády GE. CCTOP: a consensus constrained TOPology prediction web server. Nucleic acids Res. 2015:43(W1):W408-12.

51. Käll L, Krogh A, Sonnhammer EL. Advantages of combined transmembrane topology and signal peptide prediction-the Phobius web server. Nucleic acids Res. 2007;35:W429-32.

52. Peng J, Schwartz D, Elias JE, Thoreen CC, Cheng D, Marsischky G, et al. A proteomics approach to understanding protein ubiquitination. Nat Biotechnol. 2003;21(8):921.

53. Londesborough J, Richard P, Valkonen M, Viljanen K. Effect of C-terminal protein tags on pentitol and L-arabinose transport by Ambrosiozyma monospora Lat1 and Lat2 transporters in Saccharomyces cerevisiae. Appl Environ Microbiol. 2014;80(9):2737-45.

54. Knoshaug EP, Vidgren V, Magalhães F, Jarvis EE, Franden MA, Zhang $M$, et al. Novel transporters from Kluyveromyces marxianus and Pichia guilliermondii expressed in Saccharomyces cerevisiae enable growth on L-arabinose and D-xylose. Yeast. 2015;32(10):615-28.

55. Young EM, Tong A, Bui H, Spofford C, Alper HS. Rewiring yeast sugar transporter preference through modifying a conserved protein motif. Proc Natl Acad Sci USA. 2014;111(1):131-6.

56. Wang C, Li Y, Qiu C, Wang S, Ma J, Shen Y, et al. Identification of important amino acids in Gal2p for improving the L-arabinose transport and metabolism in Saccharomyces cerevisiae. Front Microbiol. 2017:8:1391.

57. Sun L, Zeng X, Yan C, Sun X, Gong X, Rao Y, et al. Crystal structure of a bacterial homologue of glucose transporters GLUT1-4. Nature. 2012;490(7420):361-6.

58. Verhoeven MD, Bracher JM, Nijland JG, Bouwknegt J, Daran JMG, Driessen AJ, et al. Laboratory evolution of a glucose-phosphorylationdeficient, arabinose-fermenting S. cerevisiae strain reveals mutations in GAL2 that enable glucose-insensitive L-arabinose uptake. FEMS Yeast Res. 2018;18(6):062.
59. Farwick A, Bruder S, Schadeweg V, Oreb M, Boles E. Engineering of yeast hexose transporters to transport D-xylose without inhibition by D-glucose. Proc Natl Acad Sci USA. 2014;111(14):5159-64.

60. Wang M, Yu C, Zhao H. Identification of an important motif that controls the activity and specificity of sugar transporters. Biotechnol Bioeng. 2016;113(7):1460-7.

61. Wittek A, Dreyer I, Al-Rasheid KA, Sauer N, Hedrich R, Geiger D. The fungal UmSrt1 and maize ZmSUT1 sucrose transporters battle for plant sugar resources. J Integr Plant Biol. 2017;59(6):422-35.

62. Wright EM, Loo DD, Hirayama BA. Biology of human sodium glucose transporters. Physiol Rev. 2011;91(2):733-94.

63. Hazama A, Loo D, Wright E. Presteady-state currents of the rabbit $\mathrm{Na}^{+}$ /glucose cotransporter (SGLT1). J Membr Biol. 1997;155(2):175-86.

64. Boorer KJ, Loo D, Wright EM. Steady-state and presteady-state kinetics of the $\mathrm{H}^{+}$/hexose cotransporter (STP1) from Arabidopsis thaliana expressed in Xenopus oocytes. J Biol Chem. 1994;269(32):20417-24.

65. Loo DD, Hirayama BA, Cha A, Bezanilla F, Wright EM. Perturbation analysis of the voltage-sensitive conformational changes of the $\mathrm{Na}^{+}$/ glucose cotransporter. J Gen Physiol. 2005;125(1):13-36.

66. Herold S, Bischof R, Metz B, Seiboth B, Kubicek CP. Xylanase gene transcription in Trichoderma reesei is triggered by different inducers representing different hemicellulosic pentose polymers. Eukaryot Cell. 2013;12(3):390-8.

67. IImen M, Saloheimo A, Onnela ML, Penttilä ME. Regulation of cellulase gene expression in the filamentous fungus Trichoderma reesei. Appl Environ Microbiol. 1997;63(4):1298-306.

68. Niemi P, Faulds CB, Sibakov J, Holopainen U, Poutanen K, Buchert J. Effect of a milling pre-treatment on the enzymatic hydrolysis of carbohydrates in brewer's spent grain. Bioresource Technol. 2012;116:155-60.

69. Landowski CP, Huuskonen A, Wahl R, Westerholm-Parvinen A, Kanerva A, Hänninen AL, et al. Enabling low cost biopharmaceuticals: a systematic approach to delete proteases from a well-known protein production host Trichoderma reesei. PLoS ONE. 2015;10(8):e0134723.

70. Benz JP, Chau BH, Zheng D, Bauer S, Glass NL, Somerville CR. A comparative systems analysis of polysaccharide-elicited responses in Neurospora crassa reveals carbon source-specific cellular adaptations. Mol Microbiol. 2014;91(2):275-99.

71. Benocci T, Aguilar-Pontes MV, Zhou M, Seiboth B, Vries RP. Regulators of plant biomass degradation in ascomycetous fungi. Biotechnol Biofuels. 2017;10(1):152.

72. Benocci T, Aguilar-Pontes MV, Kun RS, Lubbers RJ, Lail K, Wang M, et al. Deletion of either the regulatory gene ara 1 or metabolic gene xki1 in Trichoderma reesei leads to increased CAZyme gene expression on crude plant biomass. Biotechnol Biofuels. 2019;12(1):1-20.

73. Wang B, Li J, Gao J, Cai P, Han X, Tian C. Identification and characterization of the glucose dual-affinity transport system in Neurospora crassa: pleiotropic roles in nutrient transport, signaling, and carbon catabolite repression. Biotechnol Biofuels. 2017;10(1):17.

74. Vidgren V, Londesborough J. Overexpressed maltose transporters in laboratory and lager yeasts: localization and competition with endogenous transporters. Yeast. 2018;35(10):567-76.

75. Wang C, Shen Y, Hou J, Suo F, Bao X. An assay for functional xylose transporters in Saccharomyces cerevisiae. Anal Biochem. 2013:442(2):241-8.

76. Paulsen PA, Custódio TF, Pedersen BP. Crystal structure of the plant symporter STP10 illuminates sugar uptake mechanism in monosaccharide transporter superfamily. Nat commun. 2019;10(1):1-8.

77. Bisson LF, Fan Q, Walker GA. Sugar and glycerol transport in Saccharomyces cerevisiae. In: Ramos J, Sychrova H, Kschischo M, editors. Yeast membrane transport of Advances in experimental medicine and biology, vol. 892. Cham: Springer; 2016. p. 125-68.

78. Jansen ML, Bracher JM, Papapetridis I, Verhoeven MD, de Bruijn H, de Waal PP, et al. Saccharomyces cerevisiae strains for second-generation ethanol production: from academic exploration to industrial implementation. FEMS Yeast Res. 2017;17(5):044

79. de Kok S, Kozak BU, Pronk JT, van Maris AJ. Energy coupling in Saccharomyces cerevisiae: selected opportunities for metabolic engineering. FEMS Yeast Res. 2012;12(4):387-97.

80. Seiboth B, Metz B. Fungal arabinan and L-arabinose metabolism. Appl Microbiol Biotechnol. 2011;89(6):1665-73. 
81. Sherman F. Getting started with yeast. In: Guthrie C, Fink GR, editors. Guide to yeast genetics and molecular biology-part B of Methods in enzymology, vol. 350. Amsterdam: Elsevier; 2002. p. 3-41.

82. Gietz RD, Woods RA. Yeast transformation by the LiAc/SS carrier DNA/ PEG method. In: Xiao W, editor. Yeast protocols of methods in molecular biology, vol. 313. Totowa: Springer; 2006. p. 107-20.

83. Penttilä M, Nevalainen $H$, Rättö M, Salminen E, Knowles J. A versatile transformation system for the cellulolytic filamentous fungus Trichoderma reesei. Gene. 1987:61(2):155-64.

84. Lee ME, DeLoache WC, Cervantes B, Dueber JE. A highly characterized yeast toolkit for modular, multipart assembly. ACS Synth Biol. 2015;4(9):975-86.

85. Minet M, Dufour ME, Lacroute F. Complementation of Saccharomyces cerevisiae auxotrophic mutants by Arabidopsis thaliana cDNAs. Plant J. 1992;2(3):417-22.

86. Liang H, Gaber RF. A novel signal transduction pathway in Saccharomyces cerevisiae defined by Snf3-regulated expression of HXT6. Mol Biol Cell. 1996;7(12):1953-66.

87. Ma H, Kunes S, Schatz PJ, Botstein D. Plasmid construction by homologous recombination in yeast. Gene. 1987;58(2-3):201-16.

88. Winston F, Dollard C, Ricupero-Hovasse SL. Construction of a set of convenient Saccharomyces cerevisiae strains that are isogenic to S288C. Yeast. 1995;11(1):53-5

89. Sikorski RS, Hieter P. A system of shuttle vectors and yeast host strains designed for efficient manipulation of DNA in Saccharomyces cerevisiae. Genetics. 1989;122(1):19-27.

90. Clémençon B, Fine M, Schneider P, Hediger MA. Rapid method to express and purify human membrane protein using the Xenopus oocyte system for functional and low-resolution structural analysis. In: Shukla AK, editor. Membrane proteins-production and functional characterization of Methods in enzymology, vol. 556. Waltham: Elsevier; 2015. p. 241-65.

91. Steiger MG, Mach RL, Mach-Aigner AR. An accurate normalization strategy for RT-qPCR in Hypocrea jecorina (Trichoderma reesei). J Biotechnol. 2010;145(1):30-7.

92. Livak KJ, Schmittgen TD. Analysis of relative gene expression data using real-time quantitative PCR and the $2^{-\triangle \Delta C T}$ method. Methods. 2001;25(4):402-8.2- $-\Delta m C_{m T}$

93. Edgar R, Domrachev M, Lash AE. Gene Expression Omnibus: NCBI gene expression and hybridization array data repository. Nucleic acids Res. 2002;30(1):207-10.

94. Porciuncula JdO, Furukawa T, Shida Y, Mori K, Kuhara S, Morikawa Y, et al. Identification of major facilitator transporters involved in cellulase production during lactose culture of Trichoderma reesei PC-3-7. Biosci Biotechnol Biochem. 2013;77(5):1014-22.
95. Ries L, Pullan ST, Delmas S, Malla S, Blythe MJ, Archer DB. Genome-wide transcriptional response of Trichoderma reesei to lignocellulose using RNA sequencing and comparison with Aspergillus niger. BMC genomics. 2013;14(1):541.

96. Li X, Chomvong K, Yu VY, Liang JM, Lin Y, Cate JH. Cellobionic acid utilization: from Neurospora crassa to Saccharomyces cerevisiae. Biotechnol Biofuels. 2015;8(1):1-9.

97. Cai P, Wang B, Ji J, Jiang Y, Wan L, Tian C, et al. The putative cellodextrin transporter-like protein CLP1 is involved in cellulase induction in Neurospora crassa. J Biol Chem. 2015;290(2):788-96.

98. Antonieto ACC, Nogueira KMV, de Paula RG, Nora LC, Cassiano MHA, Guazzaroni ME, et al. A novel Cys2His2 zinc finger homolog of AZF1 modulates holocellulase expression in Trichoderma reesei. Msystems. 2019:4(4):e00161-19.

99. Madeira F, Lee J, Buso N, Gur T, Madhusoodanan N, Basutkar P, et al. The EMBL-EBI search and sequence analysis tools APIs in 2019. Nucleic acids Res. 2019; https://www.ebi.ac.uk/Tools/msa/muscle/. Accessed 17 Dec 2019.

100. Jones DT, Taylor WR, Thornton JM. The rapid generation of mutation data matrices from protein sequences. Bioinformatics. 1992;8(3):275-82.

101. Kumar S, Stecher G, Li M, Knyaz C, Tamura K. MEGA X: molecular evolutionary genetics analysis across computing platforms. Mol Biol Evol. 2018;35(6):1547-9.

102. Paradis E, Schliep K. ape 5.0: an environment for modern phylogenetics and evolutionary analyses in R. Bioinformatics. 2019;35(3):526-8.

103. Bodenhofer U, Bonatesta E, Horejš-Kainrath C, Hochreiter S. msa: an $\mathrm{R}$ package for multiple sequence alignment. Bioinformatics. 2015:31(24):3997-9.

104. Truernit E, Stadler R, Baier K, Sauer N. A male gametophyte-specific monosaccharide transporter in Arabidopsis. Plant J. 1999;17(2):191-201.

105. Truernit E, Schmid J, Epple P, Illig J, Sauer N. The sink-specific and stress-regulated Arabidopsis STP4 gene: enhanced expression of a gene encoding a monosaccharide transporter by wounding, elicitors, and pathogen challenge. Plant Cell. 1996;8(12):2169-82.

106. Poschet $G$, Hannich B, Büttner M. Identification and characterization of AtSTP14, a novel galactose transporter from Arabidopsis. Plant Cell Physiol. 2010;51(9):1571-80.

107. Caron L, Rousseau F, Gagnon É, Isenring P. Cloning and functional characterization of a cation-Cl cotransporter-interacting protein. J Biol Chem. 2000;275(41):32027-36.

\section{Publisher's Note}

Springer Nature remains neutral with regard to jurisdictional claims in published maps and institutional affiliations.
Ready to submit your research? Choose BMC and benefit from:

- fast, convenient online submission

- thorough peer review by experienced researchers in your field

- rapid publication on acceptance

- support for research data, including large and complex data types

- gold Open Access which fosters wider collaboration and increased citations

- maximum visibility for your research: over 100M website views per year

At BMC, research is always in progress.

Learn more biomedcentral.com/submissions 